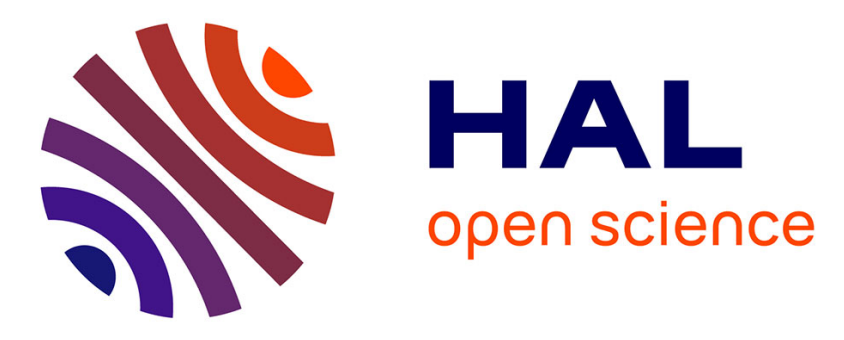

\title{
Structural Characterization of Hydrothermal Carbon Spheres by Advanced Solid-State MAS 13 C NMR Investigations
}

Niki Baccile, Guillaume Laurent, Florence Babonneau, Franck Fayon, Maria-Magdalena Titirici, Markus Antonietti

\section{To cite this version:}

Niki Baccile, Guillaume Laurent, Florence Babonneau, Franck Fayon, Maria-Magdalena Titirici, et al.. Structural Characterization of Hydrothermal Carbon Spheres by Advanced Solid-State MAS 13 C NMR Investigations. Journal of Physical Chemistry C, 2009, 113 (22), pp.9644-9654. 10.1021/jp901582x . hal-00393439

\section{HAL Id: hal-00393439 \\ https://hal.science/hal-00393439}

Submitted on 3 Feb 2017

HAL is a multi-disciplinary open access archive for the deposit and dissemination of scientific research documents, whether they are published or not. The documents may come from teaching and research institutions in France or abroad, or from public or private research centers.
L'archive ouverte pluridisciplinaire HAL, est destinée au dépôt et à la diffusion de documents scientifiques de niveau recherche, publiés ou non, émanant des établissements d'enseignement et de recherche français ou étrangers, des laboratoires publics ou privés. 
IMPORTANT NOTE: Please be aware that slight modifications occurring after Proof correction may occur between this version of the manuscript and the version on the Publisher's website

\section{Structural Characterization of Hydrothermal Carbon}

\section{spheres by Advanced Solid-State MAS ${ }^{13} \mathrm{C}$ NMR}

\section{Investigations}

Niki Baccile $^{1,2 *}$, Guillaume Laurent ${ }^{2}$, Florence Babonneau ${ }^{2}$, Franck Fayon ${ }^{3}$, Maria-Magdalena Titirici $^{1}$, Markus Antonietti $^{1}$

1-Max-Planck Institute for Colloids, Research Campus Golm, D-14424 Potsdam, Germany

2-UPMC Univ Paris 06 and CNRS, UMR 7574, Chimie de la Matière Condensée de Paris, F75005, Paris, France

3-CNRS, UPR3079, CEMHTI - Conditions Extrêmes et Matériaux : Haute Température et Irradiation, F-45071, Orléans cedex 2, France and Université d’Orléans, Faculté des Sciences, Avenue du Parc Floral, BP 6749, 45067 Orléans cedex 2, France

RECEIVED DATE (to be automatically inserted after your manuscript is accepted if required according to the journal that you are submitting your paper to)

\section{CORRESPONDING AUTHOR FOOTNOTE}

* Corresponding Author. E-mail: niki.baccile@upmc.fr, Fax: +33144274769

+ UPMC Univ Paris 06, Laboratoire de Chimie de la Matière Condensée de Paris, 4 place Jussieu, F-75005, Paris, France 
ABSTRACT The local structure of carbon spheres obtained via the hydrothermal carbonization process is characterized by using a combination of advanced solid-state ${ }^{13} \mathrm{C}$ NMR techniques. Glucose was chosen as the starting product because it offers the possibility of ${ }^{13} \mathrm{C}$ isotopic enrichment and is regarded as a model compound for more complex polysaccharides and biomass, as reported in recent studies. A number of ${ }^{13} \mathrm{C}$ solid-state MAS NMR techniques (single pulse, cross polarization (CP), inversion recovery cross polarization (IRCP), INEPT, ${ }^{13} \mathrm{C}-{ }^{13} \mathrm{C}$ proton-driven magnetization exchange and ${ }^{13} \mathrm{C}-{ }^{13} \mathrm{C}$ double quantum-single quantum (DQ-SQ) correlation experiments) were combined to retrieve information about binding motifs and C-C closest neighbor relations. We found that the core of the carbonaceous scaffold is composed of furan rings crosslinked by domains containing short keto-aliphatic chains instead of otherwise expected graphenetype sheets, as mainly reported either for hydrothermal carbon spheres or for biomass-related carbons obtained by low-temperature $\left(<350^{\circ} \mathrm{C}\right)$ pyrolisis treatment.

KEYWORDS. Carbon, Biomass, Hydrothermal Carbonization, Glucose, ${ }^{13} \mathrm{C}$ solid-state MAS NMR, Double quantum NMR.

\section{Introduction}

In a series of recent publications ${ }^{1-5}$ a sustainable approach to the synthesis of powders, mesoporous, or nanostructured carbon materials using biomass as starting product was presented: carbohydrates and raw biomass treated at relatively low temperatures $\left(160<\mathrm{T}<220^{\circ} \mathrm{C}\right)$ in water in autoclave can provide a carbonaceous colloidal spheres and particles with roughly 60-70 w\% carbon content. Different reasons motivated these works. Firstly, there is a need to explore new cheap and sustainable ways to obtain chemicals ${ }^{6}$ and advanced functional carbon materials from sustainable raw materials to replace on the long run crude oil. Secondly, in case of a really cheap pathway and useful mass products, recycling the byproducts of farmed biomass would additionally 
be a way to sequester significant amounts of $\mathrm{CO}_{2}$, creating a material benefit at the same time. The way our group approached the topic was the use of hydrothermal synthesis between $180^{\circ} \mathrm{C}$ and $220^{\circ} \mathrm{C}$ to obtain carbon-based colloidal spheres ${ }^{1,2,15}$, nanofibers ${ }^{7,8}$ or sponge-like mesoporous carbons being meaningful as soil conditioner, ion exchange resins or sorption coals ${ }^{3,5}$. The synthesis proved to be feasible when glucose ${ }^{2}$ is used or even when raw biomass materials like oak leafs and orange peals are taken ${ }^{3}$. In the first case, surface chemistry could also be modified by mean of hydrophilic $^{5}$ or hydrophobic coupling agents ${ }^{9}$. Along similar lines, the group of Clark showed that a slightly different approach using expanded starch could provide functional materials with disordered mesoporosity, which proved to be satisfactory as catalysts in the esterification of succinic acid $^{10,11}$.

In order to use the material for applications in catalysis, chromatography or as storage materials, it is evident that both a control of the chemistry behind the process and a satisfactory knowledge of the final material structure are of primary importance. In spite of the undoubted usefulness of the recent re-discovery of the hydrothermal process to obtain carbonaceous material, some basic work is still lacking as far as process of formation and final structure of the C-C-network are concerned. Some groups tried to investigate, directly or indirectly, the reaction mechanisms which transforms glucose first into its three times dehydrate intermediate, 5-hydroxymethyl-furfural-1-aldehyde $(\mathrm{HMF})^{12,13,14}$ and then subsequently to the carbonaceous scaffold ${ }^{15,16}$ but a clear description of the final structure and, consequently, of the reaction path leading to the carbonaceous material is still missing. The amorphous nature and the intrinsic chemical complexity are the main drawbacks preventing an easy and full comprehensive structural study using common techniques, like XRD or infrared spectroscopy. Nevertheless, FT-IR and in some cases FT-Raman spectroscopy have been the most popular, easily accessible, techniques used to discriminate between various functional groups $\left(\mathrm{C}=\mathrm{O}, \mathrm{C}=\mathrm{C}\right.$, aliphatic carbons) so $\mathrm{far}^{3,14,15}$. XPS was also used to identify the main carbon sites but the spectral resolution is often worse than the one obtained using vibrational spectroscopies ${ }^{9}$. Even ${ }^{13} \mathrm{C}$ solid-state $\mathrm{NMR}$ has already been tempted ${ }^{4,14,15}$ but mainly to 
complement other techniques. As for IR data, the resulting spectra only helped in the identification of the main organic functions. However, the rather good spectral resolution obtained on those hydrothermal carbons suggested that they deserved deeper investigation with more advanced NMR techniques.

Solid-state NMR studies on a large variety of carbonaceous materials, especially in soils and sediments, have already been performed, and a number of contributions have used ${ }^{13} \mathrm{C} \mathrm{NMR}^{17-}{ }^{27}$ to identify chemical species and to refine carbon structures. The most common experiments use ${ }^{1} \mathrm{H}$ to ${ }^{13} \mathrm{C}$ cross polarization (CP) technique coupled to Magic Angle Spinning (MAS), which has the advantage of signal enhancement leading to reasonable acquisition times with respect to ${ }^{13} \mathrm{C}$ single pulse MAS NMR experiments. Unfortunately, quantification using CP is more challenging than in a single pulse experiment due to the more complicated spin dynamics. On the contrary, single pulse (SP) experiments, which are largely preferred to $\mathrm{CP}$ for quantification, are generally timeconsuming. Extensive signal broadening coming from the potential presence of paramagnetic centers can also be a complicating factor, but this has not really prevented deep investigations of coals or chars by solid-state $\mathrm{NMR}^{28}$. Cross polarization at one single contact time is in general the fastest approach to obtain preliminary information about chemical composition. For improvement, Sullivan $^{18}$ presented CP experiments at variable contact times together with acquisition under modified CP conditions and two dimensional ${ }^{13} \mathrm{C}$ homonuclear magnetization exchange experiments to attribute large line widths to inhomogeneous broadening effects. Dela Rosa et al. ${ }^{19}$ studied ${ }^{1} \mathrm{H}$ longitudinal relaxation times in the laboratory frame $\mathrm{T}_{1}$ as well as in the rotating frame $\mathrm{T}_{1 \rho}$ and performed CRAMPS experiments on various coals to discriminate the presence of large amount of oxygenated sites. Finally, Tekely et al. ${ }^{20}$ employed the ${ }^{13} \mathrm{C}$ transverse dephasing times $\mathrm{T}_{2}$ ' to differentiate, based on proton mobility, aliphatic and aromatic components in overlapping signals.

We have recently found ${ }^{29}$ by a combination of ${ }^{13} \mathrm{C}$ solid state MAS NMR and SEM that whatever the complexity of hexose carbohydrates (glucose, amylopectin or starch) used in the coalification 
process is, the NMR response and in part the particle morphology of final carbons are very close, indicating the existence of a similar chemical coalification process in behind. Very similar ${ }^{13} \mathrm{C}$ NMR spectra of carbons have indeed also been reported by other authors both after hydrothermal treatment of starch ${ }^{4}$ and fructose ${ }^{15}$ and also from pyrolytic treatment at moderate temperatures $(<$ $350^{\circ} \mathrm{C}$ ) of a variety of biomass-derived sources like rice hulls ${ }^{30}$, pectin ${ }^{25}$, $\operatorname{starch}^{31}$ or cellulose ${ }^{32}$. This is an important precondition to ensure that the structural study on carbon obtained from ${ }^{13} \mathrm{C}$ enriched glucose reported in the present paper has broader validity. ${ }^{13} \mathrm{C}$ isotopic enrichment (which would be more demanding for complex biomass) is a requirement to enable a complete NMR study that combines advanced methods, as recently illustrated on the structural characterization of ${ }^{13} \mathrm{C}$ labeled graphite oxide ${ }^{33}$.

The goal of the present contribution is to show that hydrothermal carbon from ${ }^{13} \mathrm{C}$ isotopically enriched $\mathrm{D}(+)$-glucose is a good model to analyze the chemical connection motifs of biomassderived carbons obtained either via a hydrothermal or pyrolysis step at temperatures below $350^{\circ} \mathrm{C}$. This goal is achieved by combining ${ }^{13} \mathrm{C}$ solid-state MAS NMR methods such as one-dimensional (single pulse, CPMAS, IRCP, through-bond C-H filtering -INEPT-), and two-dimensional experiments $\left({ }^{13} \mathrm{C}-{ }^{13} \mathrm{C}\right.$ exchange spectroscopy and through space ${ }^{13} \mathrm{C}$ homonuclear double-quantum single-quantum correlation).

\section{Experimental Section}

Sample Preparation. For all samples, about $15 \mathrm{ml}$ of a deionized water solution containing 10 wt\% in mass of $\mathrm{D}(+)$-Glucose (with the diverse isotope labeling discussed below) is sealed into a glass vial inside a typical PTFE-lined autoclave system for hydrothermal reaction at $180^{\circ} \mathrm{C}$ for $24 \mathrm{~h}$. After reaction, the autoclave is cooled down in a water bath at room temperature. The obtained black solid powder is then separated from the remaining aqueous solution by centrifugation (7000 rpm for 20 minutes) and dried at $80^{\circ} \mathrm{C}$ in a oven under vacuum during 12 hours. Non-enriched $\mathrm{D}(+)$-glucose (Aldrich, CAS: 50-99-7), D-(+)-Glucose-1- $\left({ }^{13} \mathrm{C}\right)$ labeled at the $\mathrm{C}_{1}$-position (Aldrich, 
CAS: 40762-22-9) and fully labeled D-Glucose- ${ }^{13} \mathrm{C}_{6}$ (Aldrich, CAS:110187-42-3) have been used to prepare the samples that are listed in Table 1.

Table 1 Molar ratios of non-enriched, fully and selectively enriched glucose samples used in this study.

\begin{tabular}{cccc}
\hline & $\begin{array}{c}\text { Non-enriched } \\
\mathrm{D}(+) \text {-glucose }\end{array}$ & $\begin{array}{c}\text { Partially enriched } \\
\text { D-glucose-1- }{ }^{13} \mathrm{C}\end{array}$ & $\begin{array}{c}\text { Fully enriched } \\
\text { D-glucose- }{ }^{13} \mathrm{C}_{6}\end{array}$ \\
\hline HC0 & 100 & - & - \\
HC20 & 80 & 20 & - \\
HC80 & 20 & - & 80
\end{tabular}

GC-MS experiments have been performed with an Agilent Technologies (GC=6890N; MS= 5975) apparatus.

NMR experiments. Solution ${ }^{13} \mathrm{C}$ NMR experiments (acquisition with power-gated decoupling using a $30^{\circ}$ flip angle) were performed on a Bruker Avance $400 \mathrm{MHz}(9.4 \mathrm{~T}$ ) spectrometer with a BBO gradient coil for 5mm tubes probe head.

${ }^{1} \mathrm{H}$ and ${ }^{13} \mathrm{C}$ solid-state MAS NMR experiments have been acquired on a Bruker Avance $300 \mathrm{MHz}$ (7 T) spectrometer using $4 \mathrm{~mm}$ zirconia rotors spinning at a MAS frequency of $v_{\text {MAS }}=14 \mathrm{kHz} .{ }^{1} \mathrm{H}$ and ${ }^{13} \mathrm{C}$ chemical shifts were referenced relative to tetramethylsilane (TMS; $\delta=0 \mathrm{ppm}$ ).

Single pulse MAS experiments: pulse lengths (90 ${ }^{\circ}$ flip angle) for ${ }^{13} \mathrm{C}$ and ${ }^{1} \mathrm{H}$ were 3.15 and 3.80 $\mu \mathrm{s}$ and the optimum recycle delays were $30 \mathrm{~s}$ and $3 \mathrm{~s}$, respectively. Two-pulse phase-modulated (TPPM) proton decoupling ${ }^{34}$ was applied during ${ }^{13} \mathrm{C}$ acquisition $(80 \mathrm{kHz})$. Number of transients was 4 for ${ }^{1} \mathrm{H}$ (all samples) and 64 for ${ }^{13} \mathrm{C}$ experiments (HC80). Spectra have been decomposed with DMFIT2004 software ${ }^{35}$. Integration values should be considered with a $10 \%$ error coming from a trial and error methodology used in the fitting procedure.

CP-MAS experiments: recycle delay for all CP experiments was $3 \mathrm{~s}$ and TPPM decoupling was applied during signal acquisition. Cross-polarization transfers were performed using adiabatic tangential ramps ${ }^{36,37}$ to enhance the transfer efficiency with respect to other known methods ${ }^{38}$ and 
the CP contact time was $\mathrm{t}_{\mathrm{CP}}=3$ ms unless otherwise indicated. NS = 1840 (HC0), 440 (HC20), 32 (HC80). All FIDs were subjected to an exponential multiplication (EM) function with a Line Broadening value of $\mathrm{LB}=50 \mathrm{~Hz}$ prior Fourier transform

IRCP experiments: in order to get a complete spectral editing in CP MAS NMR, inversion recovery cross polarization (IRCP) is generally used. The principle of this sequence is reported elsewhere $^{39,40,41,42,43}$ and the only modification compared to the classical CP sequence is the introduction of a phase inversion during the contact time. ${ }^{13} \mathrm{C}$ transverse magnetization is firstly created during a relatively long contact time, $t_{C P}$, and is then progressively inverted during an inversion time, $t_{i}$. The dynamics of inversion is similar to the polarization dynamics in a standard CP sequence ${ }^{44}$, and thus strongly depends on the ${ }^{13} \mathrm{C}-{ }^{1} \mathrm{H}$ dipolar coupling. This sequence is therefore very sensitive to the local proton environment and to molecular motion and a careful analysis of the CP dynamics allows a clear distinction between the various ${ }^{13} \mathrm{CH}_{\mathrm{x}}$ sites depending on the $\mathrm{x}$ value and also between rigid and mobile ${ }^{13} \mathrm{CH}_{\mathrm{x}}$ sites. The main advantage of this experiment relative to the standard CP sequence is that the magnetization starts from an optimum value, then decreases and eventually becomes negative when increasing $t_{i}$. It is thus easy to visualize differences in inversion dynamics of various signals especially when they overlap. On the basis of theoretical arguments, the relative rates of polarization are expected to be as follows: ${ }^{45}$

$$
\mathrm{CH}_{3} \text { (static) }>\mathrm{CH}_{2}>\mathrm{CH}>\mathrm{CH}_{3} \text { (rotating), C(non-protonated) }
$$

For the IRCP experiments, a contact time $t_{\mathrm{CP}}=3 \mathrm{~ms}$ was chosen in order to maximize the polarization of the ${ }^{13} \mathrm{C}$ nuclei, while 21 spectra were recorded for various inversion times, $t_{i}$, ranging from $1 \mu$ s to $5 \mathrm{~ms}$. The recycle delays between pulses was $3 \mathrm{~s}$ and number of transient was 128.

INEPT experiments: Insensitive Nuclear Enhanced by Polarization Transfer (INEPT) experiments are commonly used in liquid state ${ }^{46,47}$ to enhance the sensitivity of ${ }^{13} \mathrm{C}$ nuclei and to detect only protonated carbon sites and to edit them according to their specific $\mathrm{J}_{\mathrm{CH}}$ coupling constants. Refocused INEPT experiments described in references ${ }^{48,49,50}$ are more adapted to solid-state 
samples since they allow to detect in-phase line shapes, avoiding cancellation effect in the case of broad ${ }^{13} \mathrm{C}$ resonances. In general, they reveal to be challenging when the proton resonances are subjected to a large homogeneous broadening due to strong ${ }^{1} \mathrm{H}$ homonuclear dipolar couplings. As clearly shown by Elena et al. ${ }^{50}$, the presence of strong ${ }^{1} \mathrm{H}$ homonuclear dipolar interaction makes both the ${ }^{1} \mathrm{H}$ and ${ }^{13} \mathrm{C}$ transverse dephasing times very short in rigid organic solids and leads to a very weak efficiency of the refocused INEPT experiments. In such case, the use of a proton homonuclear dipolar decoupling sequence is required to minimize the transverse dephasing of coherences and to recover an efficient INEPT transfer. ${ }^{50}$ In our case, the absence of ${ }^{1} \mathrm{H}$ homonuclear dipolar decoupling during the magnetization transfert and refocusing delay makes the efficiency of the experiment very low. The best INEPT efficiency obtained experimentally was below 5\% of the theoretical maximum efficiency and was achieved using very short magnetization transfert and refocusing delays corresponding both to one rotor period ( $\Delta 3+\Delta 4=0.134 \mathrm{~ms})$. Therefore, the number of transients to record the refocused INEPT spectrum of our ${ }^{13} \mathrm{C}$-enriched sample was almost 200 times higher (number of transient is 12600) than that of the single pulse MAS acquisition. For this experiment, the recycle delay was $3 \mathrm{~s}$ and TPPM decoupling was applied during signal acquisition.

Two-dimensional (2D) NMR:

- CPMAS ${ }^{13} \mathrm{C}$ homonuclear double-quantum single-quantum (DQ-SQ) correlation experiments. ${ }^{13} \mathrm{C}$ homonuclear DQ-SQ correlation spectra have been recorded at a spinning frequency of $14 \mathrm{kHz}$ using the SC14 pulse sequence described in reference 51. Based on double quantum (DQ) dipolar recoupling between spin-1/2 nuclei, this experiment is a robust way to evidence the $\mathrm{C}$ - $\mathrm{C}$ atomic spatial proximities. We have employed the SC14 sequence ${ }^{51}$ which requires a lower ratio of ${ }^{13} \mathrm{C}$ nutation frequency to spinning frequency (3.5) than other known DQ recoupling sequences like C7 ${ }^{52}$, POSTC7 ${ }^{53}$ or SPC5 ${ }^{54}$. Experimentally, this allows an efficient DQ excitation and reconversion with the use of a lower ${ }^{1} \mathrm{H}$ decoupling radio frequency field which should match almost 3 times the ${ }^{13} \mathrm{C}$ radio frequency field ${ }^{54}$. For this experiment, enhancement of ${ }^{13} \mathrm{C}$ signal was 
obtained via a first CP step described above $\left(\mathrm{t}_{\mathrm{CP}}=3 \mathrm{~ms}\right)$ and followed by double quantum excitation $\left(\tau_{\mathrm{E}}\right)$ and reconversion $\left(\tau_{\mathrm{R}}\right)$ delays. Proton decoupling was applied both during DQ excitation and reconversion (continuous wave, $v_{1 \mathrm{H}}=110 \mathrm{kHz}$ ) and signal acquisition (TPPM, $v_{1 \mathrm{H}}=78 \mathrm{kHz}$ ). The type and amplitude of proton decoupling during DQ excitation and reconversion were finely tuned on both ${ }^{13} \mathrm{C}$-glycine and ${ }^{13} \mathrm{C}$ - $\mathrm{D}(+)$-glucose and were found to be coherent with what was already proposed in terms of DQ efficiency. The DQ excitation and reconversion periods were both set to $285.7 \mu$ s corresponding to two rotor periods. $16 t_{1}$ increments with 304 scans each were collected and quadrature detection in the indirect dimension was achieved using the States method ${ }^{55}$. Exponential apodization with a line broadening factor of $\mathrm{LB}=50 \mathrm{~Hz}$ was applied in both dimension prior Fourier transform.

- CPMAS ${ }^{1} \mathrm{H}-{ }^{13} \mathrm{C}$ Heteronuclear Correlation (HETCOR). Through-space heteronuclear correlation experiment between ${ }^{1} \mathrm{H}$ and ${ }^{13} \mathrm{C}$ have been performed using a standard $2 \mathrm{D}$ version of the $\mathrm{CP}$ sequence, detailed elsewhere ${ }^{56}$. Acquisition conditions for the CP experiment were given above. Here, $16 \mathrm{t}_{1}$ increments with 64 transients each were recorded and quadrature detection was achieved using the States method ${ }^{55}$.

$-{ }^{13} \mathrm{C}-{ }^{13} \mathrm{C}$ proton-driven magnetization exchange spectroscopy: ${ }^{13} \mathrm{C}$ homonuclear proton-driven magnetization exchange 2D spectra ${ }^{57}$ have been recorded using a standard pulse sequence ${ }^{58,59}$ in which ${ }^{13} \mathrm{C}$ transverse magnetization is created using standard single pulse excitation instead of classical CP step. The mixing time for ${ }^{13} \mathrm{C}-{ }^{13} \mathrm{C}$ proton-driven magnetization exchange was set to 150 ms. Proton decoupling was applied during both indirect $t_{1}$ and direct $t_{2}$ signal. 96 t1 increments with 32 transients each were recorded and quadrature detection in the indirect dimension was realized using the States method.

\section{Results}


GC-MS was performed in the liquid phase after different times of reaction, including the aqueous phase after 24 hours reaction time. The main component in all GC curves (results not shown) is a peak whose mass and fragmentation analysis suggests an attribution to hydroxymethylfurfural (HMF), the well-known dehydration product of glucose at high temperature ${ }^{14,60,61,62,63}$. Besides HMF, one finds at least 10 additional organic substances, the most prominent being levulinic acid, dihydroxyacetone and formic acid ${ }^{63}$. This result seems to be corroborated by the ${ }^{13} \mathrm{C}$ NMR spectrum analysis of the liquid phase of the extracted sample HC0 shown in Figure 1.

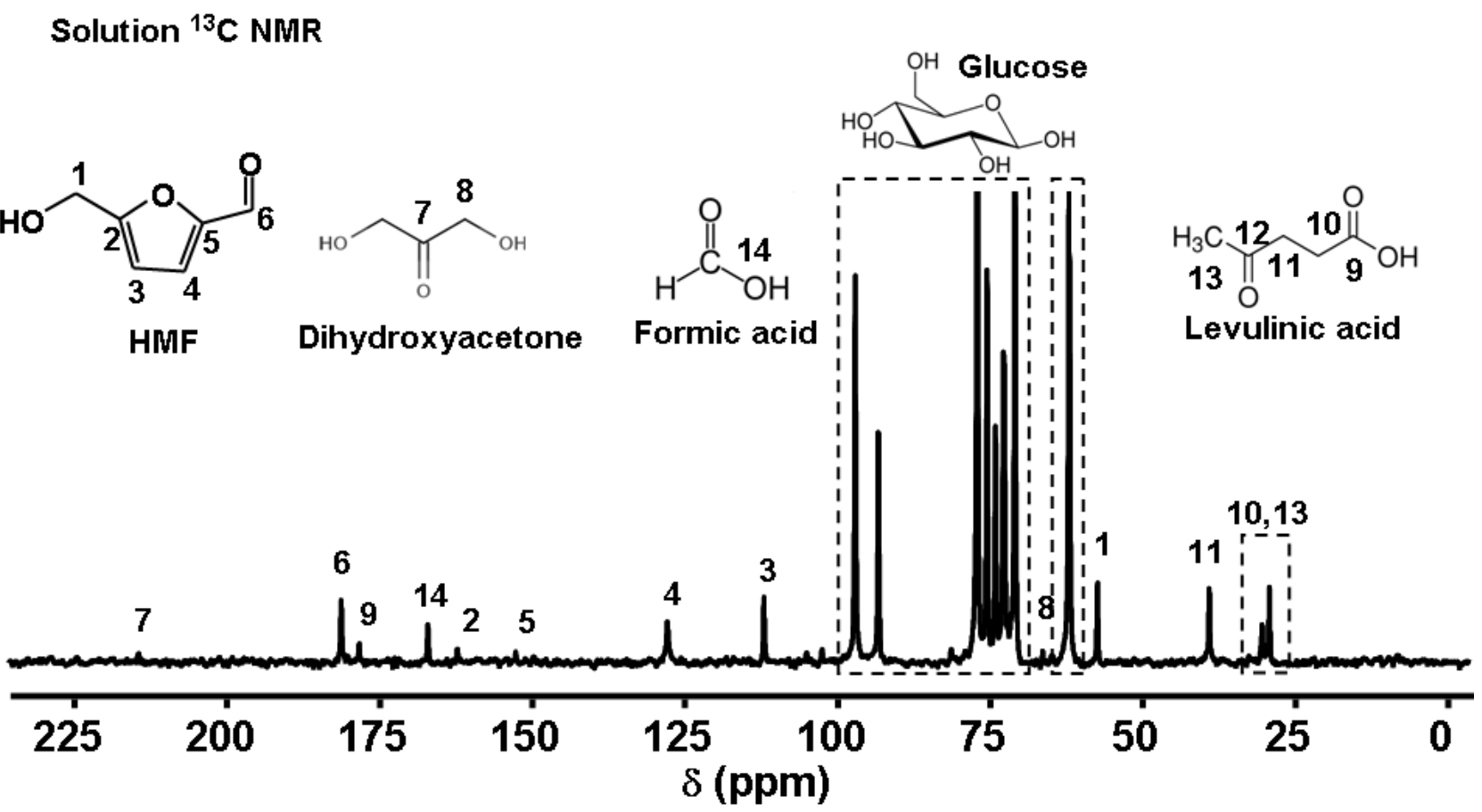

Figure $1-{ }^{13} \mathrm{C}$ solution NMR of extracted liquors after synthesis of HC0 sample (recycle delay= 2s; number of transient is 17138)

Two main sets of peaks are detected, and they can be indexed as follows ${ }^{64}$ : signals labeled from 1 to 6 are attributed to $\operatorname{HMF}\left(\mathrm{C}_{6}: 180.9, \mathrm{C}_{2}: 161.8, \mathrm{C}_{5}: 152.3, \mathrm{C}_{4}: 127.3, \mathrm{C}_{3}: 111.4, \mathrm{C}_{1}: 56.5 \mathrm{ppm}\right)$ as confirmed by ${ }^{13} \mathrm{C}$ NMR of the reference compound in $\mathrm{D}_{2} \mathrm{O}$ (result not shown); peaks labeled from 9 to 13 are attributed to levulinic acid ( $\left.\mathrm{C}_{9}: 178.4, \mathrm{C}_{11}: 37.8, \mathrm{C}_{13}: 29.7, \mathrm{C}_{10}: 27.9 \mathrm{ppm}\right)$ while peak 14 $\left(\mathrm{C}_{14}=166.2 \mathrm{ppm}\right)$ is attributed to formic acid; both compounds are expected by-product of HMF dehydration, whose presence is abundantly detected in the liquors by GC-MS experiments ${ }^{29}$; traces of dihydroxyacetone (or related products) can also be identified by the carbonyl and methylene 
peaks at, respectively, 214.5 and 65.3 ppm. Peaks in the 100-60 ppm region are attributed to unreacted glucose, even though their intensities (hence the amount of glucose) may vary from one reaction set to another. These findings support the general view that glucose first mainly dehydrates towards HMF, which on one side decomposes to form a mixture of mainly levulinic acid and formic acid $^{63,65}$ and on the other side reacts at high temperature to form the carbonaceous scaffold. Re-use of the aqueous phase in a second reaction under similar conditions resulted in further carbon phase formation and a complete elimination of the HMF peak.

The average chemical composition in weight-\% of the resulting carbonaceous solids is C: $62 \pm$ 3\%, H: $4 \pm 1 \%$, O: $34 \pm 3 \%$, which corresponds to the following molar formula $\mathrm{CH}_{0.77} \mathrm{O}_{0.41}$. The large $\mathrm{H}$ content will be favorable to ${ }^{1} \mathrm{H}-{ }^{13} \mathrm{C}$ through-space (CP) or through-bond (INEPT) heteronuclear polarization transfer NMR experiments that will help in the identification of the various sites.

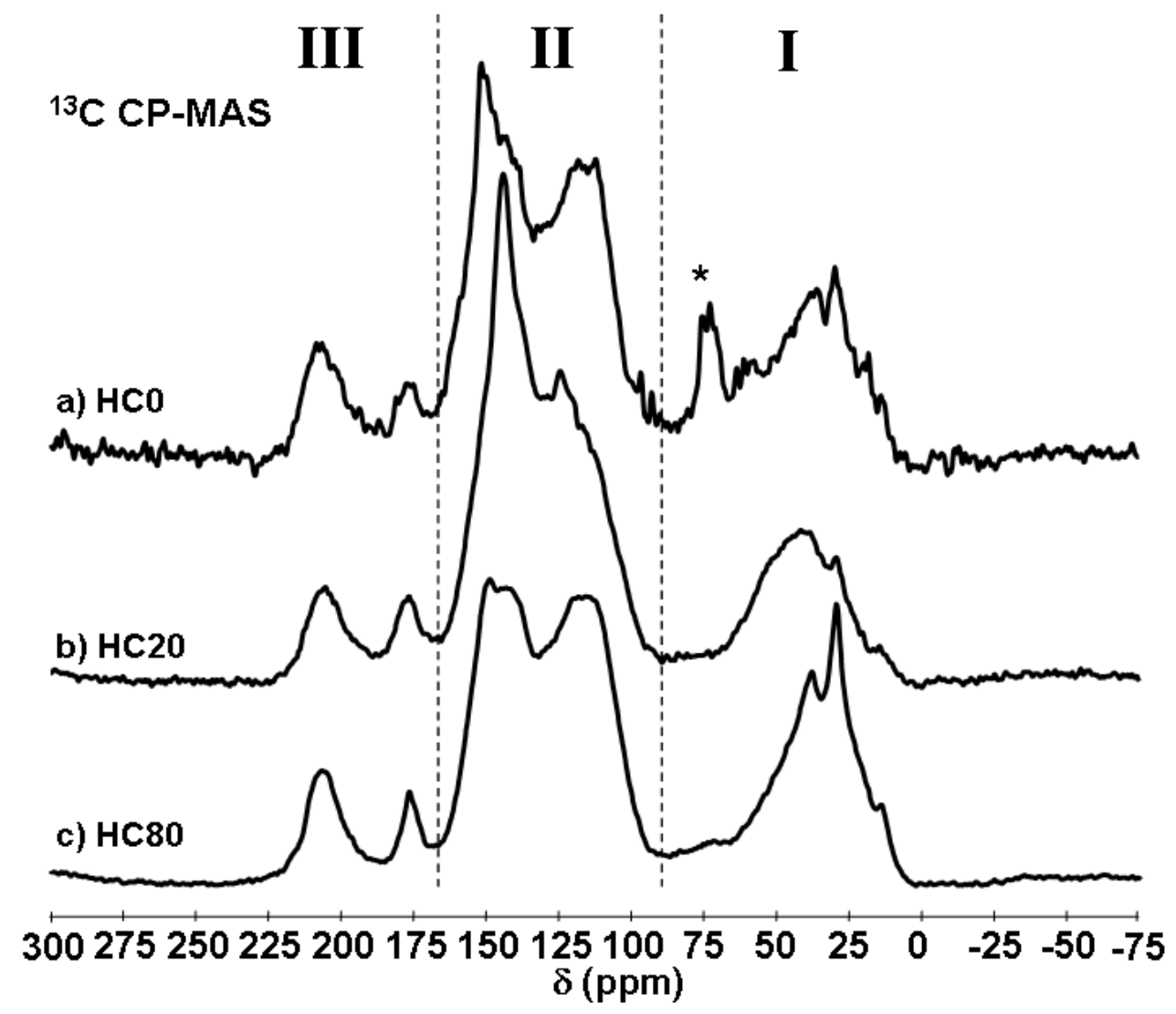

Figure $2-{ }^{13} \mathrm{C}$ CP-MAS NMR experiments of samples a) HC0, b) HC20, and c) HC80 obtained with contact time $\mathbf{t C P}_{\mathbf{C}}=\mathbf{3} \mathrm{ms}$. 
Figure 2 shows the ${ }^{13} \mathrm{C}$ solid-state CP MAS NMR spectra of hydrothermal carbon samples (Table 1) obtained from pure glucose (HC0), a mixture of pure and fully-enriched glucose (HC80) and a mixture of pure and selectively-enriched glucose-1-13 $\mathrm{C}$ (HC20) recorded using a contact time of 3 ms. A primary qualitative attribution based on literature ${ }^{17-27}$ can be proposed for each spectral domain. Region I (0-100 ppm) is characteristic of $\mathrm{sp}^{3}$ carbon atoms indicating the presence of a broad distribution of $\mathrm{CH}_{\mathrm{x}}(\mathrm{X}=1,2,3)$ sites. Region II (100 to $\left.160 \mathrm{ppm}\right)$ is characteristic of $\mathrm{sp}^{2}$ carbon atoms in $\mathrm{C}=\mathrm{C}$ double bonds with signals between 140 and $160 \mathrm{ppm}$ more specifically due to oxygen bound, $\mathrm{O}-\underline{\mathrm{C}}=\mathrm{C}, \mathrm{sp}^{2}$ carbons. In region III (170-225 ppm), $\mathrm{C}=\mathrm{O}$ groups either in carboxylic acid moieties (175 ppm) or ketones and aldehydes (200-220 ppm) resonate. Finally, a peak at 75 ppm, whose intensity largely varies among all materials, corresponds to residual glucose, as also compared to the large amount of residual glucose in the solution phase. 


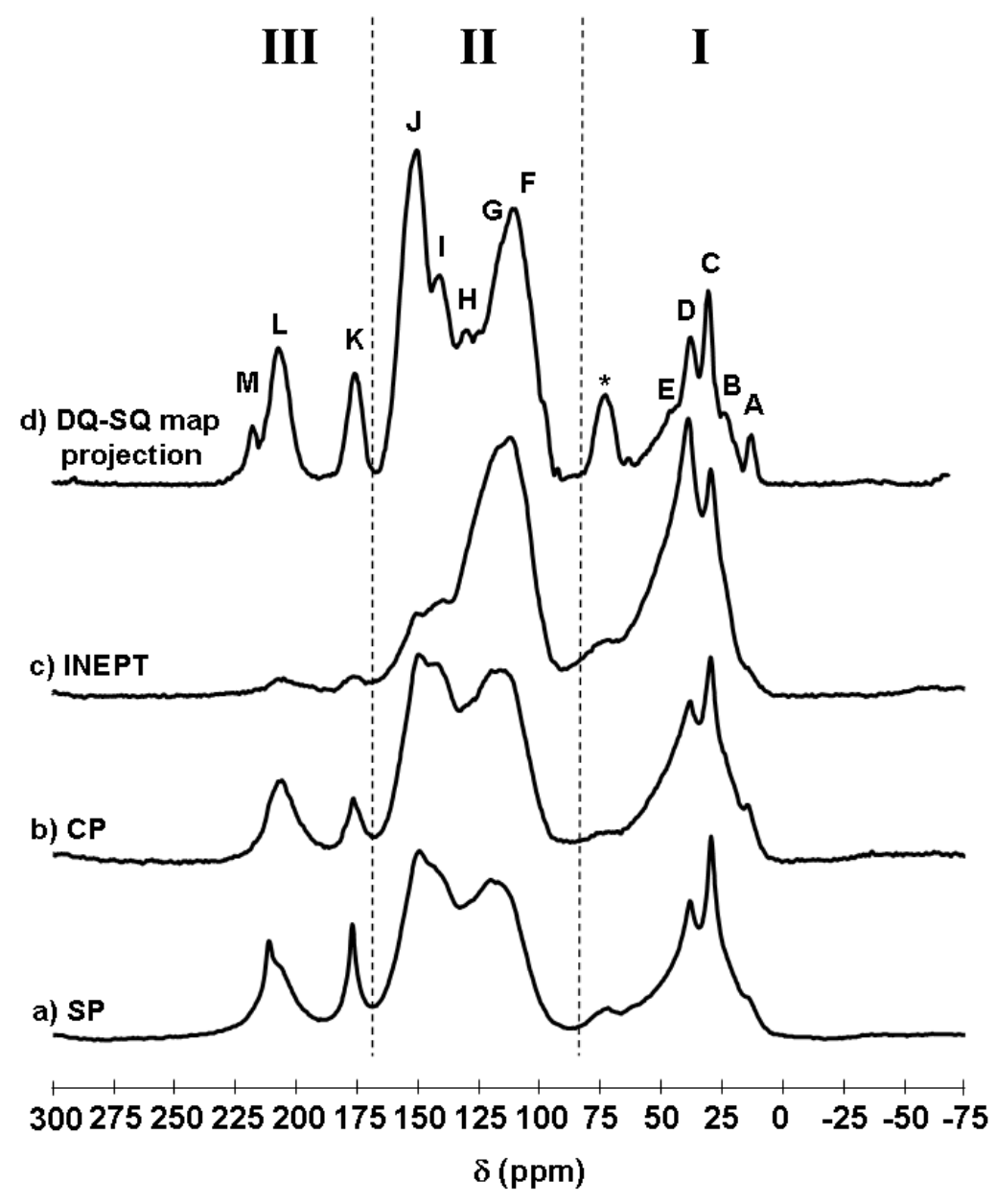

Figure $3-{ }^{13} \mathrm{C}$ MAS NMR spectra of sample HC80 recorded with various sequences: a) SP, b) CP and c) INEPT. d) Skyline projection of the $2 \mathrm{D}^{13} \mathrm{C}-{ }^{13} \mathrm{C}$ DQ-SQ experiment shown in Figure 6.

To contribute to a better understanding of the reaction mechanism, which transforms glucose into functionalized carbonaceous powders, selectively ${ }^{13} \mathrm{C}$-enriched glucose molecule in position 1 (sample HC20) was used to promote amplification of specific signals especially in the carbonyl region, as known from previous works ${ }^{60}$. However all spectra (Figure 2) look similar, which demonstrates that the ${ }^{13} \mathrm{C}$, initially in position 1 , was abundantly reshuffled through the complete monomer structure or reacting sub-species. Even if a closer observation of the spectra nevertheless shows some slight differences in the relative intensities of several peaks, we exclude at the moment the employment of specific isotope labeling for a more refined investigation of the chemical condensation mechanism. However, as expected, comparison between HC0 (acquisition time: 
5500s) and HC80 (acquisition time: 70s) shows that isotopic enrichment is extremely useful in terms of sensitivity. In addition, despite the high level of enrichment, peak broadening due to ${ }^{13} \mathrm{C}$ homonuclear dipolar couplings is not observed, showing that a MAS rate of $14 \mathrm{kHz}$ is sufficient to efficiently average out the ${ }^{13} \mathrm{C}$ homonuclear dipolar interactions, which are expected to range between 2 and $7 \mathrm{kHz}$ depending on C-C distances.

Such a high quality response allowed recording quantitative single-pulse (SP) MAS experiments on HC80 sample (Figure 3a). Very few differences can be noticed when comparing the SP to the CP-MAS spectrum recorded with a long contact time of $3 \mathrm{~ms}$ (Figure 3b), due to the large proton content $(\mathrm{H} / \mathrm{C}=0.77)$ and the presence of strong ${ }^{1} \mathrm{H}$ homonuclear dipolar coupling giving rise to efficient ${ }^{1} \mathrm{H}$ spin diffusion processes. Slight differences are mainly concentrated in the $\mathrm{C}=\mathrm{O}$ region, where the two signals around 176 and 210 ppm are clearly multi-components: 1) a sharp peak centered at $210.0 \mathrm{ppm}$ is present in the SP spectrum but hardly detected by CP; 2) similarly, the signal at $176.5 \mathrm{ppm}$ in the SP spectrum reveals the presence of a sharp peak overlapping a broader signal. The origin of these resonances is very peculiar and it will be explained in the discussion section.

It is clear so far that ${ }^{13} \mathrm{C}$ NMR spectra suggest a complex nature of the final hydrothermal carbon with the presence of a larger variety of carbon sites. In the following, the ${ }^{13} \mathrm{C}$ resonance assignments have been refined combining several ${ }^{13} \mathrm{C}$ NMR techniques. INEPT technique gives a straightforward interpretation on protonated carbon sites, as carbon signals are filtered via the through-bond J-coupling. Cross-polarization experiments have been performed at different contact times ranging from $35 \mu$ s to $7 \mathrm{~ms}$. We have found that this approach provides selective pieces of information mainly in region II characteristics of aromatic peaks. IRCP experiments were also performed at several inversion times (from $1 \mu$ s to $500 \mu \mathrm{s}$ ) and they were extremely useful in the spectral resolution of the complex multi-component aliphatic region. Finally, the $2 \mathrm{D}{ }^{13} \mathrm{C}-{ }^{13} \mathrm{C}$ DQSQ correlation spectrum was very powerful to finely resolve most of the carbon species and to establish their connectivities. Our indexation (peaks A-M in Figure 3d and Table 2) is based on this 
2D DQ-SQ correlation experiment (both using the skyline projection and the cross-peaks) and all techniques cited above; the decomposition of the skyline projection is shown in Figure 1 ESI. A detailed description of each experiment used to investigate the structure of the carbonaceous material is given in the following paragraphs.

Insight on protonated carbons by INEPT experiments. As shown in Figure 3c, definite proof of the identification of protonated carbon sites is provided by the refocused INEPT MAS experiment which allows probing ${ }^{1} \mathrm{H}-{ }^{13} \mathrm{C}$ through-bond (J-coupled) connectivities. Nevertheless, this experiment confirms the existence of protonated carbons in region I (10-50 ppm) as well as for the broad signal between 110 and $130 \mathrm{ppm}$ ( $\mathrm{sp}^{2}$ sites), and demonstrates that majority of the sites contributing to the signal centered at $150 \mathrm{ppm}$ are actually non-protonated. This is an important piece of information since it strongly suggests that the signals at $110-130$ and 150 ppm can be mainly assigned to furanic $\mathrm{O}-\mathrm{C}=\underline{\mathrm{C}} \mathrm{H}-$ and $\mathrm{O}-\underline{\mathrm{C}}=\mathrm{CH}$ - sites, respectively: indeed, similar chemical shift values are observed for $\alpha$-positions (161.8 and $152.3 \mathrm{ppm}$, see Scheme 1 ) and $\beta$-positions (111.4 and 127.3 ppm, Scheme 1) in HMF, as shown in Figure 1b. In agreement to the known chemical steps which transform glucose into HMF, we believe that this compound reacts further so that the furan ring may constitute the majority of the carbonaceous scaffold, in agreement with CP, IRCP and DQ-SQ experiments shown later. Finally, the two low-intensity signals at 176.5 and 208 ppm suggest the presence of a small amount of aldehydes with respect to typical non-protonated carbonyl sites detected in the same chemical shift range, such as ketones and carboxylic acids, and indicating the aldehyde as a preferred reaction site. Nevertheless, the presence of residual aldehyde groups was also proved by ${ }^{1} \mathrm{H}-{ }^{13} \mathrm{C}$ CP HETCOR experiments performed at relatively short contact time of $500 \mu$ s (result not shown) showing a correlation peak between the $\mathrm{C}=\mathrm{O}$ signal at $176.5 \mathrm{ppm}$ and a proton resonance at $\sim 9.0 \mathrm{ppm}$. One should remark that no cross peak was detected at 211.0 ppm, corroborating the CP data and confirming the assignment of this signal to a ketone group. 


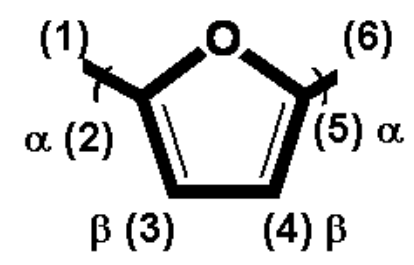

Majority species

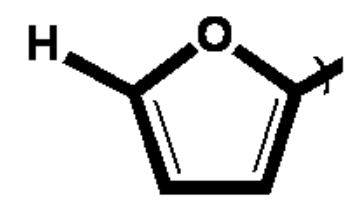

Minority species

Scheme 1 . The furan ring with the $\alpha$-position (or positions $2 ; 5)$ and $\beta$-positions (or positions 3 ;4) highlighted

Insight on aromatic carbons using $\left\{{ }^{1} \mathrm{H}\right\}-{ }^{13} \mathrm{C}$ CP experiments. Figure 4a shows $\left\{{ }^{1} \mathrm{H}\right\}-{ }^{13} \mathrm{C}$ CP MAS spectra recorded at various contact times from very short $\left(\mathrm{t}_{\mathrm{CP}}=35 \mu \mathrm{s}\right)$ to long values $\left(\mathrm{t}_{\mathrm{CP}}=10 \mathrm{~ms}\right)$. The spectrum recorded at $\mathrm{t}_{\mathrm{CP}}=35 \mu$ s mainly reveals aliphatic and $\beta$-carbons and looks very similar to the INEPT spectrum. This is expected since for short contact time magnetization transfers only occur across strong dipolar couplings corresponding to short C-H distances characteristic of C- $\mathrm{H}_{\mathrm{x}}$ bonds. ${ }^{66}$ The aliphatic zone $(10-80 \mathrm{ppm})$ of the CPMAS spectra shows a very complex shape composed of several unresolved resonances for which more insight will be provided by the IRCP experiments in the next section. However, interesting insights can be actually gained in the aromatic region (100-160 ppm, region II). Five main peaks (F, G, H, I, J) are evidenced and the corresponding evolution of the integrated area of peaks (F), (G), (J), (I) as a function of cross polarization time is shown in Figure 4b (refer to Figure 2-ESI for some CP spectra decompositions at different $t_{C P}$ values). Interestingly, peaks $(G),(I),(J)$ show the same polarization behavior, typical of a quaternary carbon (as compared to the behavior of the ketone (L)-peak at 208 ppm, reported on the graph for comparative purposes), while peak (F) shows a very fast increase in intensity, which is typical of a protonated carbon. Therefore, CPMAS experiments clearly show that peak (G), which was expected to have a similar chemical nature as peak (F) on the basis of their very close ${ }^{13} \mathrm{C}$ chemical shifts, could not be assigned to protonated carbon as peak (F) and is dominated by quaternary species. We will use this important piece of information to depict the exact nature of the carbon sites related to peaks (F) and (G) after the analysis of the 2D DQ-SQ map. One important remark: CP behavior of peak $(\mathrm{H})$ at $131.2 \mathrm{ppm}$ reveals to be typical of a quaternary carbon (not 
shown). This piece of information will provide valuable insights about the nature of this resonance in conjunction with the DQ-SQ experiment.
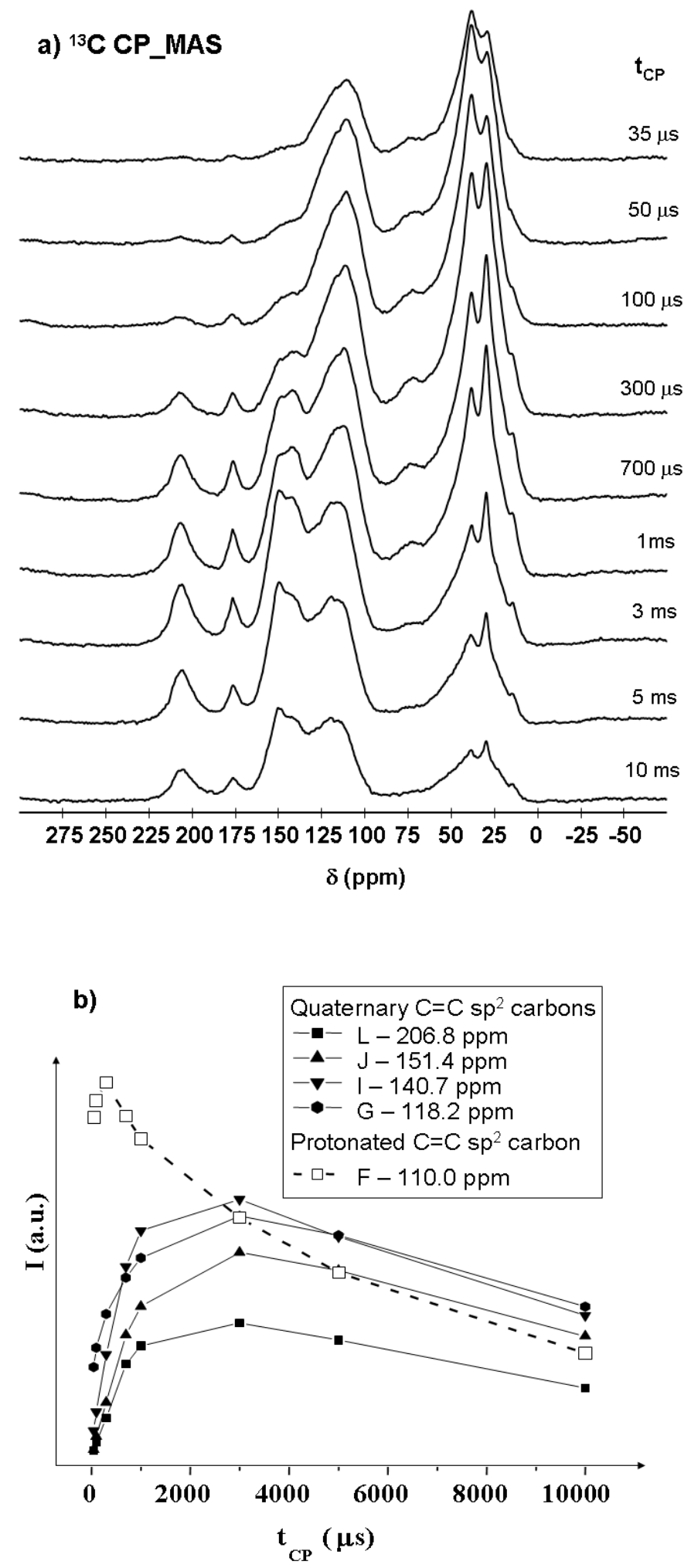

Figure 4 - Evolution of ${ }^{13} \mathrm{C}$ CP-MAS spectra recorded on $\mathrm{HC} 80$ for different contact times (a) and variation of peak intensities of aromatic region (b) as a function of the contact time 
Insight on the aliphatic region using $\left\{{ }^{1} H\right\}-{ }^{13} \mathrm{C}$ IRCP experiments. For a detailed and complete analysis of the aliphatic region where a strong overlapping of signals is observed, IRCP is a better approach than simple CP-MAS. As highlighted in the experimental part, IRCP experiments are generally selective to rigid $\mathrm{CH}_{2}$ and $\mathrm{CH}$ sites as their normalized intensity signal tends, respectively, to a negative value $(-1 / 3)$ or to zero as a function of $t_{i}$. On the contrary, signal of mobile $\mathrm{CH}_{3}$ and/or quaternary carbons remains positive. Figure 5a shows some IRCP experiments for the aliphatic region at selected inversion times; after $100 \mu$ s, the broad signal inverts exception made for two sharp components within peaks at 29.6 and 38.3 ppm. Decomposition of IRCP spectra is shown in Figure 3-ESI; typically, the set of peaks (A-E) from DQ-SQ projection (Figure 1-ESI) was used for some selected IRCP spectra. Finally, the evolution of the integrated normalized intensity as a function of the inversion time for some peaks is presented in Figure 5b. Negative intensity values occur for $\mathrm{CH}_{2}$ groups whose peaks are at 23.9 (B), 28.7 (C) and 38.3 (D) ppm; stars shows the typical behavior for mobile $\mathrm{CH}_{3}$ species, as confirmed for peak (A) at $13.9 \mathrm{ppm}$ and sharp peak (C) at 29.6 ppm belonging to $\mathrm{CH}_{3}$ groups; finally, intensity variation for peak (E) at 50.5 ppm shows the expected behavior for $\mathrm{CH}$ groups, as also confirmed by comparison to the behavior of the peak labeled $(*)$ due to the $\mathrm{CH}$ of glucose (73.4 ppm), and acting as an internal $\mathrm{CH}$ standard. Table 2 summarizes the main families of $\mathrm{CH}_{\mathrm{x}}$ groups (peaks A through E) but one should notice that peaks (C) and (D) are certainly multi-components, as resulting from the DQ-SQ projection (Figure 1-ESI) and the cross-peaks in the 2D map (next section). 


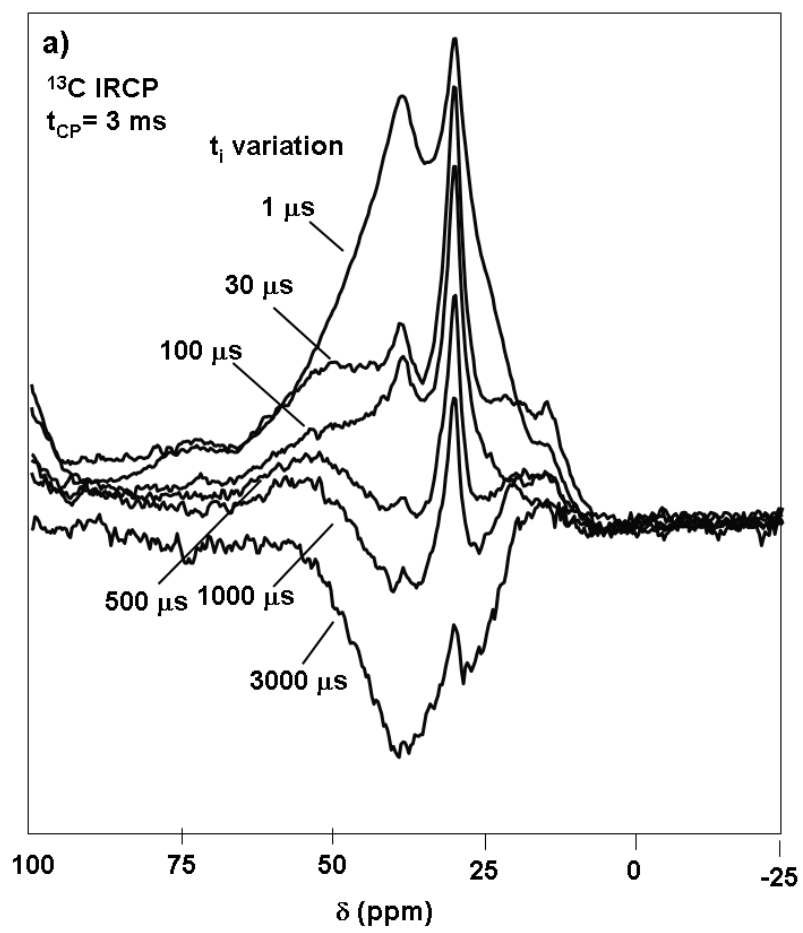

b)

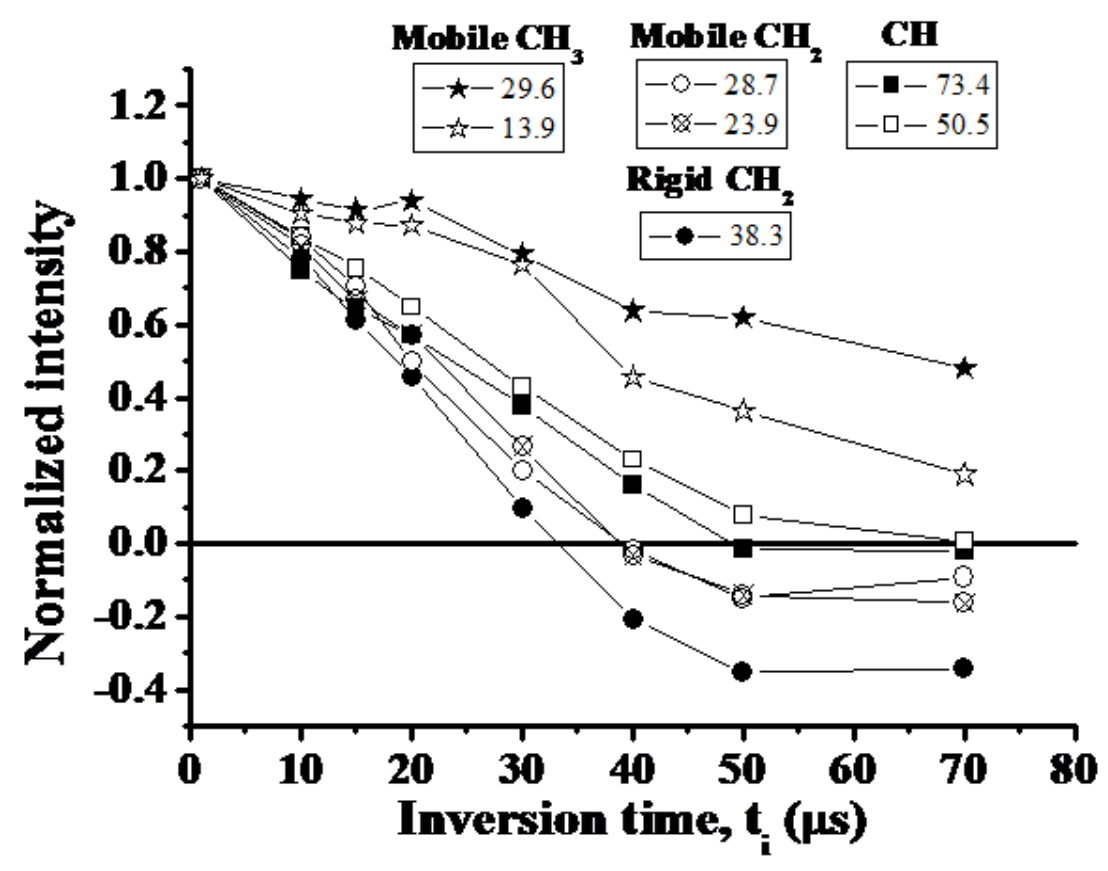

Figure 5 - a) IRCP spectra recorded at various inversion times in the aliphatic region for sample $\mathrm{HC80}$; b) evolution of IRCP peak intensity for selected decomposed peaks belonging to various $\mathrm{CH}, \mathrm{CH}_{2}$ and $\mathrm{CH}_{3}$ groups. 
Table 2 - Peak assignment for HC80 material after decompositions of: ${ }^{13}$ C DQ-SQ experiment, CP and IRCP experiments. Percentage of each carbon group was obtained by decomposition of HC80 SP spectrum.

Quantitative data only concerns carbonaceous material, not including embedded levulinic acid (see text for explanation). Remaining $4 \%$ is attributed to residual adsorbed glucose (* peak at $73.4 \mathrm{ppm})$.

\begin{tabular}{|c|c|c|c|c|c|}
\hline $\begin{array}{l}\text { Spectral } \\
\text { domain }\end{array}$ & CP/IRCP & INEPT & Peak & $\begin{array}{l}\delta\left({ }^{13} \mathrm{C}\right) \\
(\mathrm{ppm})\end{array}$ & $\begin{array}{c}\text { Percentage } \\
\%\end{array}$ \\
\hline \multirow{7}{*}{$\begin{array}{c}\mathrm{I} \\
\mathrm{sp}^{3} \mathrm{C}\end{array}$} & Mobile $\mathrm{CH}_{3}$ & \multirow{7}{*}{$\begin{array}{c}\mathrm{CH}_{\mathrm{x}} \\
\mathrm{x}=1-3\end{array}$} & A & 13.9 & \multirow{7}{*}{23} \\
\hline & Rigid $\mathrm{CH}_{2}$ & & B & 23.9 & \\
\hline & Rigid $\mathrm{CH}_{2}$ & & $\mathrm{C}$ & 28.7 & \\
\hline & Mobile $\mathrm{CH}_{3}$ & & $\mathrm{C}$ & 29.6 & \\
\hline & Mobile $\mathrm{CH}_{2}$ & & $\mathrm{D}$ & 38.3 & \\
\hline & $\mathrm{CH}$ & & $\mathrm{E}$ & 50.5 & \\
\hline & $\mathrm{CH}$ & & $*$ & 73.4 & \\
\hline \multirow{5}{*}{$\begin{array}{c}\mathrm{II} \\
\mathrm{sp}^{2} \mathrm{C}\end{array}$} & $\mathrm{CH}$ & \multirow{2}{*}{$\mathrm{CH}_{\mathrm{x}}$} & $\mathrm{F}$ & 110.0 & \multirow{2}{*}{29} \\
\hline & $\mathrm{C}$ & & G & 118.2 & \\
\hline & & & $\mathrm{H}$ & 131.2 & \multirow{3}{*}{35} \\
\hline & $\mathrm{C}$ & $\mathrm{C}$ & I & 140.7 & \\
\hline & & & $\mathrm{J}$ & 148-156 & \\
\hline \multirow{3}{*}{$\begin{array}{c}\text { III } \\
\mathrm{C}=\mathrm{O}\end{array}$} & - & $\mathrm{CH}_{\mathrm{x}}$ & $\mathrm{K}$ & $175-179$ & 4 \\
\hline & \multirow{2}{*}{-} & \multirow{2}{*}{$\mathrm{C}$} & $\mathrm{L}$ & $202-207$ & \multirow{2}{*}{9} \\
\hline & & & M & 218.4 & \\
\hline
\end{tabular}

Insight on spatial connectivity using ${ }^{13} \mathrm{C}$ homonuclear DQ-SQ correlation experiments. The experiments previously performed allowed identification of the different functions present in the carbonaceous samples but did not provide information about close spatial proximities between the various carbon groups. Indeed, several NMR methods exist to visualize short-range connectivities either via through-bond or through-space techniques: for example, the group of Emsley used double quantum excitation (INADEQUATE ${ }^{67}$ ) to probe carbon-carbon connectivities in biomass ${ }^{68}$ while a recent report used a fpRFDR ${ }^{69}$ pulse sequence to study ${ }^{13} \mathrm{C}$-labelled graphite oxide ${ }^{33}$. For our study, we strongly preferred the use of double quantum excitation; in fact, the signals lying on the diagonal in a 2D DQ-SQ experiment provides crucial pieces of information about connectivity among equivalent sites. Since we were unable to optimize a high quality INADEQUATE 
experiment on our samples, probably due to the low values and dispersion J-coupling values for $\mathrm{sp}^{2}$ and $\mathrm{sp}^{3}$ carbon sites, we performed a two-dimensional (2D) ${ }^{13} \mathrm{C}$ homonuclear double-quantum single-quantum (DQ-SQ) MAS experiment using the SC14 sequence ${ }^{51}$. This experiment allows the double quantum recoupling of dipolar-coupled spin-pairs and results in a 2D spectrum (with a direct SQ MAS dimension and an indirect DQ dimension for which the frequency corresponds to the sum of the two individual chemical shifts of the pair of coupled spins) allowing to trace out the C-C proximities between both inequivalent and equivalent sites. In the case of uniformly ${ }^{13} \mathrm{C}$ labeled samples, the DQ-SQ correlation spectra are dominated by the direct (one-bond) strong couplings due to dipolar truncation effects ${ }^{51,70,71}$ and the longer-range C-C proximities are evidenced through indirectly correlated peaks of lower and negative intensities ${ }^{51,54}$. To avoid the presence of the indirectly correlated peaks and only observe correlation peaks reflecting the one-bond C-C strong coupling, we have used short DQ excitation and reconversion times (corresponding to two rotor periods) to record the 2D CP-filtered DQ-SQ correlation spectrum of the sample HC80, which has a high ${ }^{13} \mathrm{C}$ enrichment level. Cross-peaks (93.2-72.7 ppm) and (97.0-75.1 ppm) relate to the DQ excitation of $C_{1}-C_{2}$ groups in the $\alpha$ - and $\beta$-pyranose forms of glucose (whose presence was highly abundant also in the mother liquors). This is very important as glucose acts as the internal standard proving that the $\underline{\mathrm{SC} 14}$ sequence under the employed conditions is selective to one $\mathrm{C}-\mathrm{C}$ bond length. 


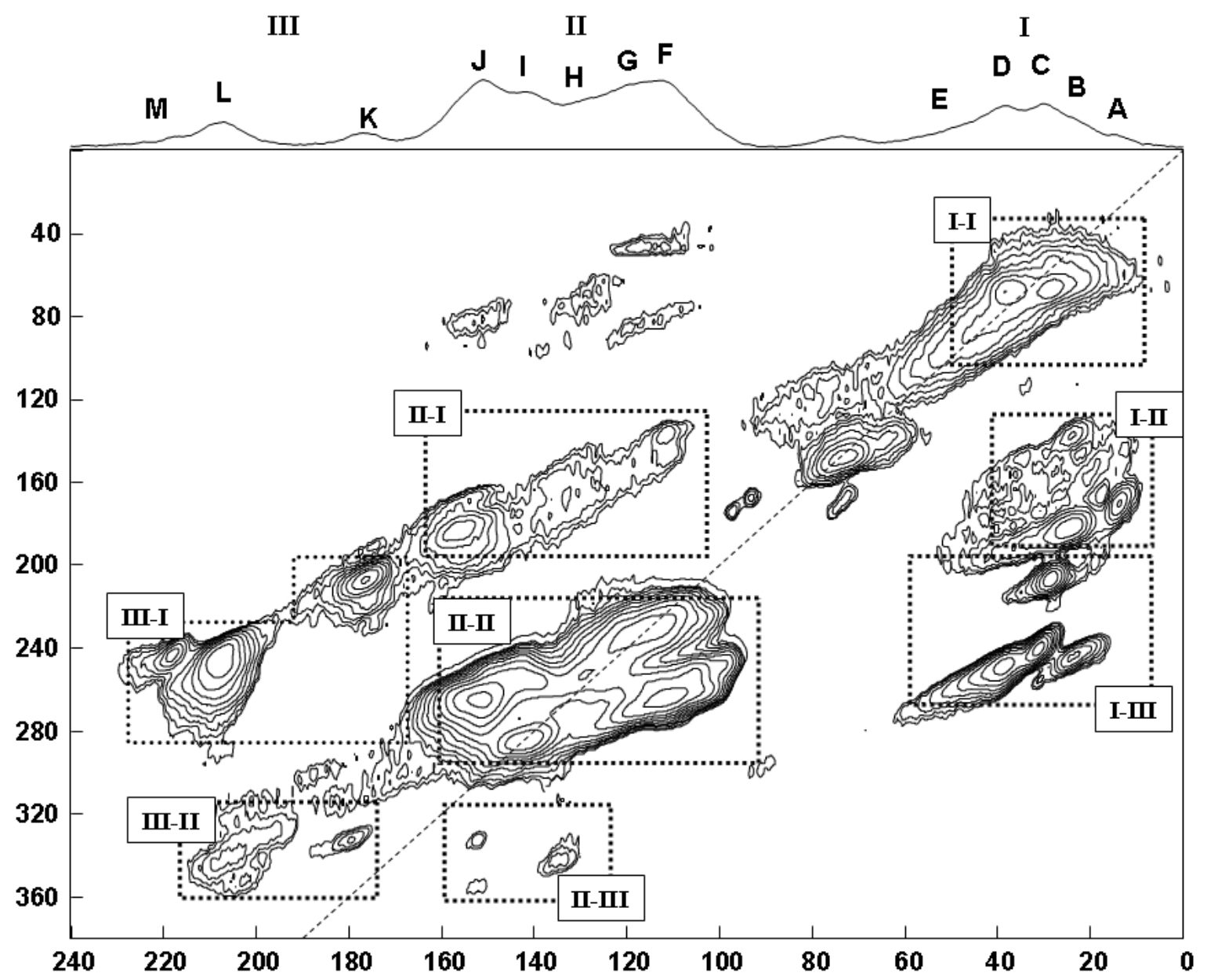

Figure 6 - 2D ${ }^{13} \mathrm{C}$ DQ-SQ MAS NMR correlation spectrum recorded on sample HC80 with $\tau_{\mathrm{E}}=\tau_{\mathrm{R}}=285.3 \mu \mathrm{s}$. Insights on the connectivity scheme are provided in Figure 4a,b-ESI

The main and most important result of the 2D DQ-SQ ${ }^{13} \mathrm{C}-{ }^{13} \mathrm{C}$ map is the visualization of the subtle connectivity among all species shown via the numerous cross-peaks and revealing the complexity of the carbon skeleton; however, they can be grouped in 5 different categories (symbolized by dashed rectangles in Figure 6), depending if they relate two carbon sites from the same spectral region (I-I and II-II) or from two different regions (I-II, I-III and II-III). The most intense correlation peaks belong to the II-II region, revealing strong homonuclear ${ }^{13} \mathrm{C}-{ }^{13} \mathrm{C}$ dipolar interactions between those $\mathrm{sp}^{2} \mathrm{C}$ sites. Peaks in the I-I region are less intense, but the dipolar coupling between $\mathrm{sp}^{3} \mathrm{C}$ is expected to be lower (longer $\mathrm{C}-\mathrm{C}$ distance and possible internal mobility). As expected, no cross-peak relates two $\mathrm{C}=\mathrm{O}$ sites from region III. Then, the most intense cross-peaks relating $\mathrm{C}$ sites from two different spectral regions are found in region I-III, showing 
that the $\mathrm{C}=\mathrm{O}$ groups are mostly bonded to $\mathrm{sp}^{3} \mathrm{C}$ sites. Fewer and less intense cross-peaks are found in regions I-II and II-III, suggesting the existence of spatially distinct domains that discriminate the $\mathrm{sp}^{2} \mathrm{C}$ sites from the others.

A closer look to the various regions will help proposing some structural motifs for the carbonaceous scaffold. For a clear trace of the connectivity on the 2D DQ-SQ map, one should refer to Figure 4-a,b-ESI.

- Aromatic core (region II-II): as established earlier by CP and INEPT experiments, region II corresponds primarily to $\alpha$-substituted furanic rings where peak (F) originates from protonated $\beta$ carbons and peaks (I) and (J) are related to non-protonated $\alpha$-carbons. For this spectral range, the DQ-SQ map shows four diagonal auto-correlation peaks (F-F, G-G, H-H and I-I) and three partly overlapping off-diagonal cross-correlation peaks (F-J), (F-I) and (G-J). The cross-correlation peaks (F-J) clearly suggest a connectivity between the $\alpha$-carbons of two furanic rings through a $\mathrm{C}=\mathrm{C}$ double bond, as shown in Scheme 2b, while the correlation peak (I-I) reveals a direct furanic connection as depicted in Scheme 2c. The auto- (G-G) and cross-correlation peaks (G-J) (F-B) indicate that quaternary $\beta$-carbons (F), (G) also constitute an important site for extra-furanic connectivity as shown in Scheme 2 d-f. To this regard, due to the equivalent amount of protonated and quaternary $\beta$-carbons (peaks F and G), as observed in SP MAS spectrum, one $\beta$-carbon out of two throughout the whole material is cross-linked. Finally, peak $(\mathrm{H})$ at $131.2 \mathrm{ppm}$, given its chemical shift (typical for extended aromatic networks), its quaternary nature (as seen by CP behavior as a function of contact time) and the presence of an auto (H-H) cross peak (though of low intensity), describes the existence of spurious domains of grapheme sheets (Scheme 2a). 


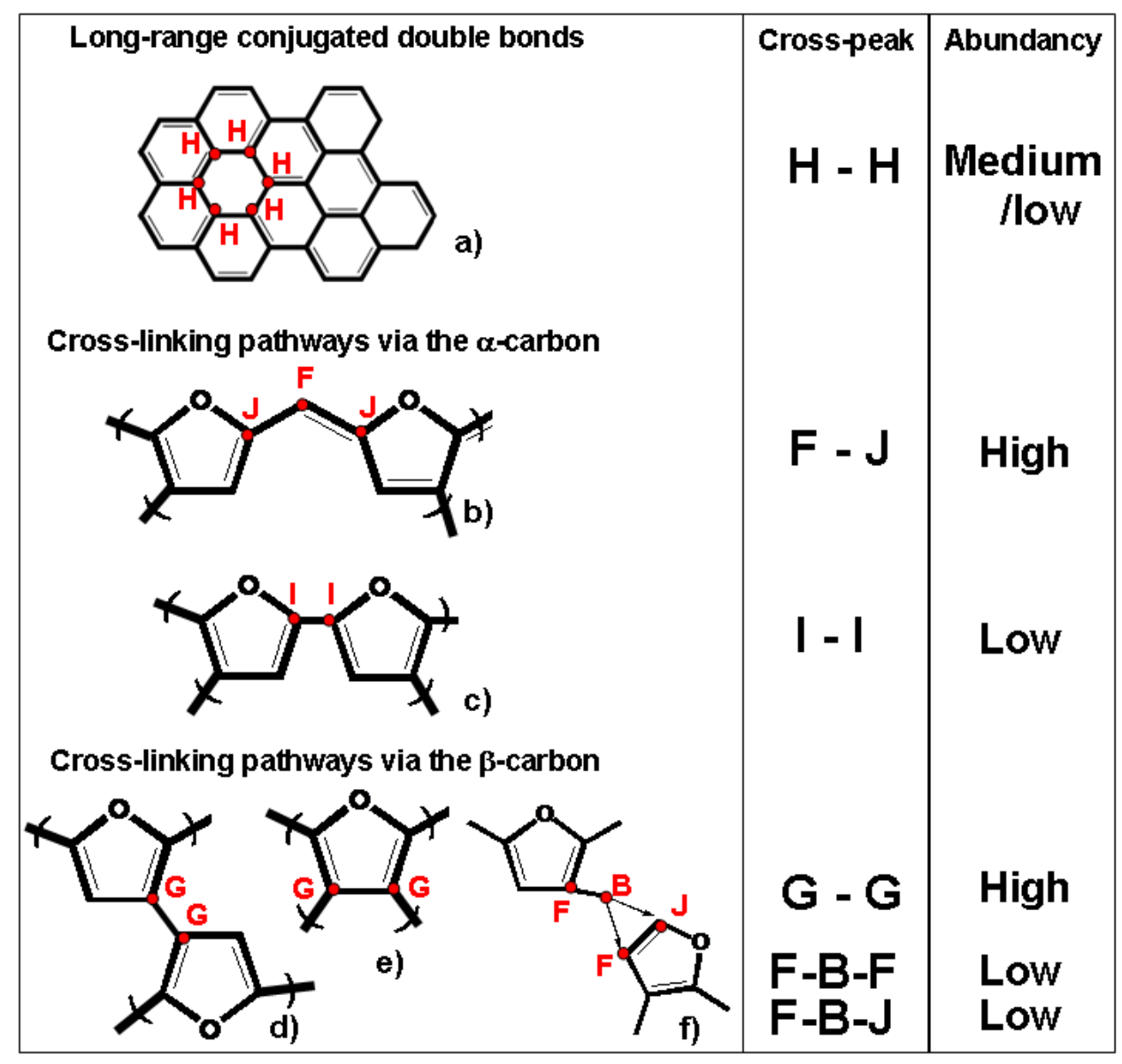

Scheme 2 - Structural motifs identified in region II-II from the 2D DQ-SQ ${ }^{13} \mathrm{C}-{ }^{13} \mathrm{C}$ correlation spectrum

Due to the intensity of the cross-peaks depicted in region II-II and the nature of the identified chemical species (Scheme 2), we believe that the core of the carbonaceous material is mainly composed of cross-linked furanic species. The chemical nature of the cross-links, spacers and possible end functions which are directly bonded to the furanic rings are described below after analyzing the correlation peaks between regions I-I, I-II, I-III and II-III.

- Cross-links between furanic groups (Region II-I and II-III): chemical functions which are directly connected to $\alpha$-carbons are shown in Scheme 3 and are related to off-diagonal cross-peaks signals found in regions II-I and II-III of the DQ-SQ map of Figure 6. Signal (B) identifies a wide distribution of $\alpha-\mathrm{CH}_{2}$ groups, which can be in turn connected to either a second furan ring 
(Scheme 3a) or to a carbonyl $\mathrm{C}=\mathrm{O}$ group (signals $\mathrm{M}$, Scheme $3 \mathrm{~b}$ ), which can be interpreted either as an aldedhyde or a ketone group connected to a (E) site at $50.5 \mathrm{ppm}$, most likely a $\mathrm{CH}$ group (see IRCP). At a lower extent, a carbonyl $\mathrm{C}=\mathrm{O}$ group can be directly bound to $\alpha$-carbons (Scheme 3c).

End functions: A low amount of direct functional groups directly linked to the furanic rings are also evidenced on the 2D correlation spectrum, as depicted in Scheme 3 d-f. Typically, aldehydic (Scheme 3d), methyl (Scheme 3e) and carboxy (Scheme 3f) groups bonded to the C $\alpha$ carbon are evidenced through the off-diagonal (J-L), (J-A) and (J-K) cross-correlation peaks, respectively. Interestingly, the connection between the graphene-like (peak H) and the rest of the material is allowed by a keto group (cross-peak H-L).

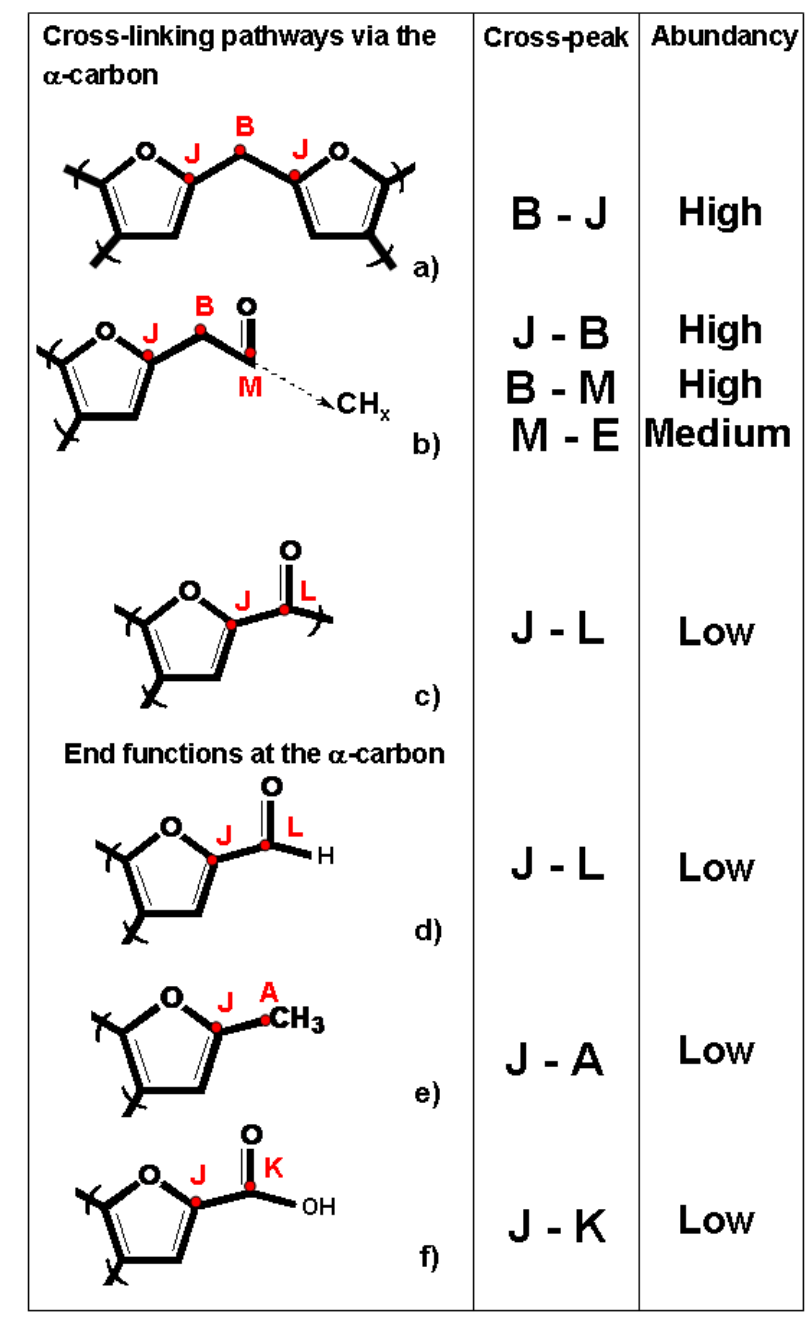

Scheme 3 - Cross-links between furanic rings and end functions at the $\alpha$-carbon identified from the 2D DQ-SQ ${ }^{13} \mathrm{C}-{ }^{13} \mathrm{C}$ correlation spectrum 
Cross-linking (Region III-I and I-I): These regions mainly show the interactions among carbons which compose the linkers between furanic moieties. Peak (B) identifies $\mathrm{CH}_{2}$ (see IRCP) cross links between furanic species (peaks $\mathrm{F}$ and $\mathrm{J}$ ): $\mathrm{C}_{\alpha}-\mathrm{CH}_{2}-\mathrm{C}_{\alpha}$ (J-B-J; high intensity), $\mathrm{C}_{\beta}-\mathrm{CH}_{2}-\mathrm{C}_{\beta}$ (FB-F but very weak intensity), $\mathrm{C}_{\alpha}-\mathrm{CH}_{2}-\mathrm{C}_{\beta}$ (J-B-F of weak intensity). Peak (E) at $50.5 \mathrm{ppm}$ is a $\mathrm{CH}$ group according to IRCP experiments. The corresponding cross-peak is very broad and difficult to analyze, as it mainly connects to ketones (E-L) even if self $\mathrm{CH}-\mathrm{CH}$ (E-E) or $\mathrm{CH}-\mathrm{CH}_{2}$ (E-D) correlation may also be possible.

Levulinic acid. All correlation peaks which have been discussed above are related to the structure of the furanic network. However, several additional intense cross-correlation peaks between region I and III are also clearly observed on the 2D correlation spectrum. This concern the (K-C) crosscorrelation peaks at about $176.5(\mathrm{~K})$ and $28.7(\mathrm{C})$ ppm in the SQ dimension, the (C-D) crosscorrelation peak at 28.7 (C) and 38.3 (D) ppm, the (D-L) cross-correlation peaks at 38.3 (D) and 208 (L) ppm and finally a (L-C) correlation peaks at 208 (L) and 29.6 (C) ppm. Firstly, this set of correlation peak clearly indicates that the C peak contains two distinct components (which overlap completely in the 1D MAS and CP MAS spectra) with isotropic chemical shifts very similar to those of reported for the $\mathrm{CH}_{3}(29.7 \mathrm{ppm})$ and $\mathrm{CH}_{2}(27.9 \mathrm{ppm})$ groups of levulinic acid in $\mathrm{CDCl}_{3}$ solution. Secondly, it evidences a K-C-D-L-C connectivity pattern which is characteristic of levulinic acid. The presence of levulinic acid was confirmed by an additional $2 \mathrm{D}{ }^{13} \mathrm{C}$ homonuclear proton-driven magnetization exchange experiment realized with mixing time of $150 \mathrm{~ms}$ without the classical $\left\{{ }^{1} \mathrm{H}\right\}-{ }^{13} \mathrm{C}$ CP step (result not shown). This approach allows the detection of all mobile species whose sensitivity is very low using a common CP approach due to molecular mobility. We were able to visualize the same connectivity pattern 29.6-210.0-38.3-28.7-176.5 ppm typical for the levulinic acid molecule. Meanwhile, sharps signals at 210.0 and 176.5 ppm which were lost after $\mathrm{CP}$ treatment were recovered and found to be coherent with peak attribution and connection related to levulinic acid. This additional experiment shows that part of LA exist in a free form within the material core. 
One final remark: the four well-defined, but weak, cross-peaks at 75 ppm (marked by an asterisk) and $(93,97) \mathrm{ppm}$ that can be attributed to the alpha and beta glucopyranose forms of glucose, as pointed out before and existing in spurious amounts (residual glucose was previously highlighted in mother liquors). It is clear from the 2D experiment that glucose does not correlate with any other carbon in the sample suggesting its simple entrapment in the carbonaceous matrix.

\section{Discussion}

All data support the idea that the main structural motif is the furan ring directly coming from HMF, the dehydration product of glucose. The very intense cross-peaks (J-F) provides the main spectroscopic evidence for this assumption: the amount of $\mathrm{C}=\mathrm{C}-\mathrm{O}$ and $\mathrm{C}=\mathrm{C}$ is close to one-to-one. Any interpretation including widespread graphene sheets decorated with $\mathrm{OH}$ groups is not consistent with our data because an intense peak at $130 \mathrm{ppm}$, in addition to the resonance above 140 ppm, would be otherwise expected. This idea was also corroborated by the fact that direct carbonization of HMF provides a material whose chemical characteristics are very close to a glucose-synthesized carbon, as shown by previous solid state NMR experiments ${ }^{29}$. However the final products of thermally-treated biomass is not just a simple polyfurane, and the obtained material is quite complex, as suggested by the combination of co-existing structures depicted in schemes 2-3. Clearly, HMF units merge together mainly via $\alpha$-carbons causing the long-range conjugated double bonded network but ramification from $\beta$-positions is also very common, as one $\beta$-carbon out of two is actually cross-linked. Interestingly, it is commonly accepted that carbon intermediates obtained from biomass pyrolisis at $\mathrm{T}<350^{\circ} \mathrm{C}$ are constituted of a long-range aromatic network with terminal hydroxyl groups, which accounts for all NMR resonances between 110 and $150 \mathrm{ppm}^{25,31,32}$. This interpretation, simply based on chemical shift assumptions from cross polarization experiments alone, is too loose to fit the whole set of our experimental data, which rely 
on a number of complementary $1 \mathrm{D}$ and 2D techniques. Even if the presence of furan moieties in the structure of carbonaceous materials was very seldom highlighted, we believe that this is actually the only coherent explanation to our data. Given the very close similarity between ${ }^{13} \mathrm{C}$ NMR spectra of hydrothermally-treated glucose, polysaccharides ${ }^{15,16}$ and pyrolyzed biomass ${ }^{25,31,32}$, it is very likely that the initial stages of carbon formation goes through a cross-linked polyfuran network.

In order to have a picture of how the internal structure of the carbonaceous powder is disposed, one should consider several points: 1 ) dimension of each particle ranges between 0.5 and $5 \mu \mathrm{m}^{29} ; 2$ ) ${ }^{13} \mathrm{C}-{ }^{13} \mathrm{C}$ DQ-SQ experiments show that most of the furan rings are strongly mutually connected, suggesting their very close spatial proximity; 3) quantitative data indicate that a fairly high amount of carbon signal (> 20\%, excluding free levulinic acid) comes from aliphatic carbons, and throughspace connectivities show that most of those groups play a cross-linking role between carbonyls and furans. These considerations clearly exclude a long-range furanic network whose external surface is decorated with aliphatic chains and carbonyl groups but it rather leads us towards an interpretation in which the micrometer-sized carbon particle is actually composed of many interconnected (through short keto-aliphatic spacers) nano-sized domains in which an arbitrary combination of structures proposed in Scheme 2-3 co-exist together. The model as described above is visualized in Scheme 4. 


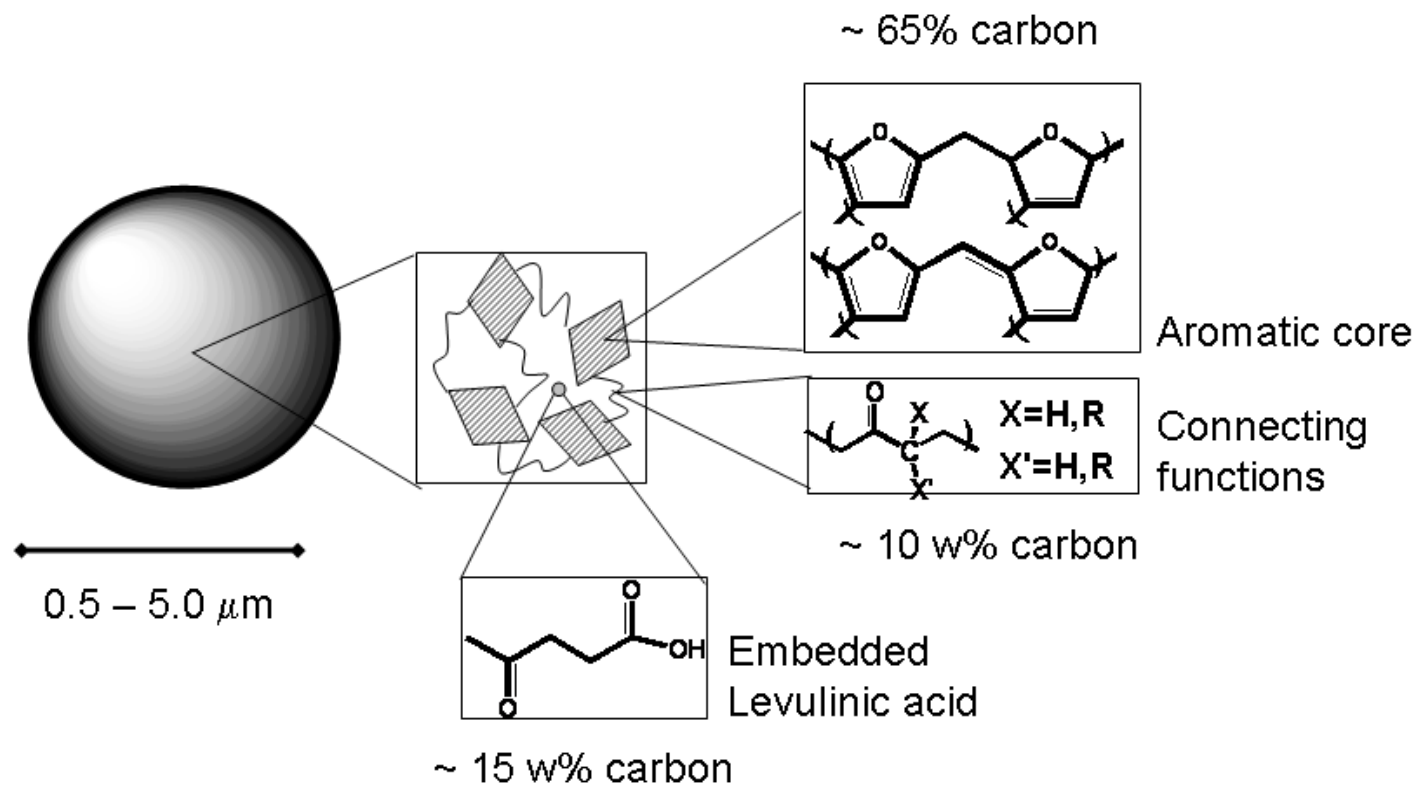

Scheme 4 - Structural model of carbon particles

Analysis of the overall intensity of the SP spectrum (Table 2) of HC80 let us attribute 13\% of carbon to $\mathrm{C}=\mathrm{O}$ containing groups, ca. $64 \%$ to $\mathrm{sp}^{2} \mathrm{C}=\mathrm{C}$ carbons (in particular about $29 \%$ to $\alpha$ carbons, $29 \%$ to $\beta$-carbons and $6 \%$ to graphene sheets) and around $23 \%$ to $\mathrm{sp}^{3}$ carbons. When comparing these values to the carbonyl content both in glucose and HMF (16.6\%), one can notice that the most carbonyl groups are kept throughout coalification. $66.6 \%$ of $\mathrm{sp}^{2} \mathrm{C}=\mathrm{C}$ carbons of $\mathrm{HMF}$ are practically kept unchanged during the process. This clearly proves that addition/polymerization of double bonds ${ }^{72}$ as a leading coalification mechanism at least does not take place without consecutive elimination steps. On the other side, the 1:1 $\alpha$-carbon to $\beta$-carbon ratio of HMF is nearly kept in the final material, which, once again, strongly supports the presence of the furan as main structural motif. The amount of the aliphatic part is in the end larger (23\%) than in HMF (16.6\%). Different mechanistic proposals can be made to account for the larger aliphatic contribution. Hydration of the aldehyde group of HMF may result in a further elimination of formic acid (this by-product is abundantly detected by GC-MS) and the consequent protonation of the $\mathrm{C}_{\alpha}$ site as proved by INEPT experiments above (scheme 1); such a proton being very labile ${ }^{73}$, a homocondensation reaction forming a direct connection between two furan rings (see cross peak I-I in 
Figure 6 and Scheme 2c) may occur. Formation of the abundant $\mathrm{CH}_{2}$ groups acting as linkers between furan rings may originate from nucleophilic addition after possible elimination of the hydroxyl group on HMF. On the contrary, the nucleophilic attack on the aldehyde group of HMF from a second furanic unit may lead to hydroxyl species which can in turn be eliminated with subsequent electron rearrangement and formation of a $\mathrm{sp}^{2} \mathrm{CH}$ carbon between two furan moieties (scheme 2b). The formation of specific $\mathrm{CH}_{3}$ and $\mathrm{COOH}$ ending groups (from $\mathrm{C} \alpha$ of furan ring) was previously reported $^{73}$ (scheme 3 e-f) while some doubts still exist on the attribution and explanation of the $\mathrm{CH}$ group at $50.5 \mathrm{ppm}$ (E). According to the DQ-SQ map, its direct connection to ketone groups has the highest probability (even $\mathrm{CH}-\mathrm{CH}$ or $\mathrm{CH}-\mathrm{CH}_{2}$ bonds may exist at a minor extent). In this case, a reaction path directing towards a bridging $\mathrm{CH}$ between three $\mathrm{C}=\mathrm{O}$ groups (this could be justified by the broadness of the E band) may not be excluded. In fact, cyclic condensation of the levulinic acid (LA) can lead to cyclic diketone species having a linking $\mathrm{CH}_{2}$ site to which a third LA molecule could react via an aldol condensation step. Further insights can probably be found in the complex chemistry of furans, as largely described and commented in reference 73.

\section{Conclusion}

In this communication we tried to address the difficult problem of the structure resolution of amorphous carbonaceous materials obtained, here, from hydrothermal carbonization processing of biomass. Based on previous comparative studies, glucose was selected as a good model carbon source since it allows the preparation of ${ }^{13} \mathrm{C}$ enriched samples and thus the use of solid-state ${ }^{13} \mathrm{C}$ NMR to investigate the chemical composition and local structure of the hydrothermally treated materials. Several standard MAS NMR techniques (SP, CP, IRCP), which are mainly used in the study of carbon structures, have been used here to identify the amount and type of $\mathrm{sp}^{2}$ and $\mathrm{sp}^{3}$ carbon sites. In addition, we used through-bond filtering techniques based on J-coupling (INEPT), which provided a clear-cut distinction between protonated and quaternary carbons. Finally, the connectivity between carbon species was identified using a $2 \mathrm{D}{ }^{13} \mathrm{C}-{ }^{13} \mathrm{C}$ correlation experiment based on double quantum excitation of through-space dipolar-coupled nuclei. 
We found that about $60 \%$ of the carbon atoms belong to a cross-linked furan-based structure. Furan moieties are either directly linked via the alpha carbon or via $\mathrm{sp}^{2}$ or $^{\mathrm{sp}} \mathrm{p}^{3}$ type carbon groups, where cross-linking can occur. Additional cross-linking sites are located at the beta carbons of the furan ring. Interestingly, we found that levulinic acid, one of the decomposition product of hydroxymethylfurfural (HMF), is highly abundant in the final material both as embedded molecule and as copolymerized compound. A clear set of CP-blind NMR signals can be related to free molecular levulinic acid (also corroborated with ${ }^{13} \mathrm{C}-{ }^{13} \mathrm{C}$ exchange spectroscopy experiments) while the $2 \mathrm{D}{ }^{13} \mathrm{C}-{ }^{13} \mathrm{C}$ DQ-SQ map suggests levulinic acid copolymerizes with the polyfuran network. We believe that such a complex structure is the result of a cascade of coexisting reactions paths of inter-furfural polymerization and aldol-condensation reactions involving both the furan motif and dehydrated glucose-based products, like levulinic acid. This more vinylic, aliphatic structure explains many of the properties of hydrothermal coal, such as rather high combustion value, high chemical reactivity, reductive properties, and high ion binding capacity and wettability. In the end, we can provide a pictorial image of the inner carbon structure obtained via hydrothermal treatment of glucose but which can be extended to depict more carbons obtained from more complex biomass both via a hydrothermal and a pyrolysis step. Interestingly, comparing these results with literature studies, it seems that the furan ring may be the actual carrying structural motif for biomass-derived carbons obtained at pyrolysis temperatures below $350^{\circ} \mathrm{C}$, in contrast with many previous reports in which the existence of oxydized graphene sheets was supposed. Here, less than $6 \%$ of all carbons are involved in such a structural motif.

\section{Acknowledgements}

We thank Prof. M. Sollogoub (IPCM, Université Pierre et Marie Curie, Paris, France) for helpful discussions.

\section{References}


${ }^{1}$ Titirici, M.-M.; Thomas, A.; Antonietti, M. New J. Chem. 2007, 31, 787

2 Titirici, M.-M.; Thomas, A.; Antonietti, M. Adv. Funct. Mater. 2007, 17, 1010

${ }^{3}$ Titirici, M.-M.; Thomas, A.; Yu, S.-H.; Muller, J.-O.; Antonietti, M. Chem. Mater. 2007, 19, 4205

${ }^{4}$ Budarin, V.; Clark, J. H.; Hardy, J. J. E.; Luque, R.; Milkowski, K.; Tavener, S. J.; Wilson, A. J. Angew. Chem. Int. Ed. 2006, 45, 3782

${ }^{5}$ Demir-Cakan, R.; Baccile, N.; Antonietti, M.; Titirici, M.-M. Chem. Mater. 2009, DOI: $10.1021 / \mathrm{cm} 802141 \mathrm{~h}$

${ }^{6}$ Corma, A.; Iborra, S.; Velty, A. Chem. Rev. 2007, 107, 2411

${ }^{7}$ Qian, H.-S.; Yu, S.-H.; Luo, L.-B.; Gong, J.-Y.; Fei, L.-F.; Liu, X.-M. Chem. Mater. 2006, 18, 2102

${ }^{8}$ Qian, H.-S.; Antonietti M.; Yu S.-H. Adv. Funct. Mater. 2007, 17, 637

${ }^{9}$ Titirici, M.-M.; Thomas, A.; Antonietti, M. J. Mater. Chem. 2007, 17, 3412

${ }^{10}$ Budarin, V.; Luque, R.; Macquarrie, D. J.; Clark, J. H. Chem. Europ. J. 2007, 13, 6914

${ }^{11}$ Budarin, V. L.; Clark, J. H. ; Luque, R. ; Macquarrie, D. J. Chem. Commun. 2007, 634

${ }^{12}$ Lourvanij, K.; Rorrer, G. L. Appl. Catal., A 1994, 109, 147

${ }^{13}$ Lourvanij, K.; Rorrer, G. L. Ind. Eng. Chem. Res. 1993, 32, 11

${ }^{14}$ Antal, M. J.; Mok, W. S. L.; Richards, G. N. Carbohyd. Res. 1990, 199, 91

${ }^{15}$ Yao, C.; Shin, Y.; Wang, L.-Q.; Windisch, C. F. Jr.; Samuels, W. D.; Arey, B. W.; Wang, C.; Risen, W. M. Jr.; Exarhos, G. J. J. Phys. Chem. C 2007, 111, 15141 
${ }^{16}$ Sun, X.; Li, Y. Angew. Chem. 2004, 116, 607

${ }^{17}$ Barron, P. F.; Wilson, M. A. Nature 1981, 289, 275

${ }^{18}$ Sullivan, M. J.; Maciel, G. E. Anal. Chem. 1982, 54, 1608

${ }^{19}$ dela Rosa, L.; Pruski, M.; Lang, D.; Gerstein, B.; Solomon, P. Energy \& Fuels 1992, 6, 460

${ }^{20}$ Tekely, P.; Nicole, D.; Brondeau, J.; Delpuech, J.-J. J. Phys. Chem. 1986, 90, 5608

${ }^{21}$ Lukins, P. B.; McKenzie, D. R.; Vassallo, A. M.; Hanna, J. V. Carbon, 1993, 31, 569

${ }^{22}$ Azami, K.; Yamamoto, S.; Sanada, Y. Carbon, 1993, 31, 611

${ }^{23}$ Fu, F.; Liu, L.; Huang, W.; Sun, P. J. Appl. Polym. Sci., 2003, 87, 2253

${ }^{24}$ Kawashima, H.; Yamada, O. Fuel Proc. Tech. 1999, 61, 279

${ }^{25}$ Sharma, R. K.; Wooten, J. B.; Baliga, V. L.; Hajaligol, M. R. Fuel 2001, 80, 1825

${ }^{26}$ Sharma, R. K.; Wooten, J. B.; Baliga, V. L.; Martoglio-Smith, P. A.; Hajaligol, M. R. J. Agric. Food Chem. 2002, 50, 771

${ }^{27}$ Holtman, K. M.; Chang, H.-M.; Jameel, H.; Kadla, J. F. J. Wood Chem. Tech. 2006, 26, 21

${ }^{28}$ Bardet, M.; Hediger, S.; Gerbaud, G.; Gambarelli, S.; Jacquot, J. F.; Foray, M. F.; Gadelle, A. Fuel 2007, 86, 1966

${ }^{29}$ Titirici, M.-M.; Antonietti, M.; Baccile, N, Green Chem. 2008, 10, 1204

${ }^{30}$ Freitas, J. C. C.; Bonagamba, T. J.; Emmerich, F. G. Carbon 2001, 39, 535

${ }^{31}$ Zhang, X.; Golding, J.; Burgar, I. Polymer 2002, 43, 5791

${ }^{32}$ Wooten, J. B.; Seeman, J. I.; Hajaligol, M. R. Energy Fuels 2004, 18, 1 
${ }^{33}$ Cai, W.; Piner, R. D.; Stadermann, F. J.; Park, S.; Shaibat, M. A.; Ishii, Y.; Yang, D.; Velamakanni, A.; An, S. J.; Stoller, M.; An, J.; Chen, D.; Ruoff, R. F. Science 2008, 321, 1815

${ }^{34}$ Bennett, A. E.; Rienstra, C. M.; Auger, M; Lakshmi, K. V.; Griffin, R. G. J. Chem. Phys. 1995, 103, 6951

${ }^{35}$ Massiot, D.; Fayon, F.; Capron, M.; King, I.; Le Calve, S.; Alonso, B.; Durand, J.-O.; Bujoli, B.; Gan, Z.; Hoatson, G. Magn. Reson. Chem. 2002, 40, 70.

${ }^{36}$ Hediger S.; Meier, B.H.; Kurur, N.D.; Bodenhausen, G.; Ernst, R.R. Chem. Phys. Lett. 1994, 223, 283

${ }^{37}$ Hediger, S.; Meier, B.H.; Ernst, R.R., Chem. Phys. Lett. 1995, 240, 449

${ }^{38}$ Christiansen, S.C.; Hedin, N.; Epping, J.D.; Janicke, M.T.; del Amo, Y.; Demarest, M.; Brzezinski, M.; Chmelka, B.F. Sol. St. Nucl. Magn. Res. 2006, 29, 170

${ }^{39}$ Cory, D. G.; Ritchey, W. M. Macromol. 1989, 22, 1611

${ }^{40}$ Tekely, P.; Montigny, F.; Canet, D.; Delpuech, J. J. Chem. Phys. Lett. 1990, 175, 401.

${ }^{41}$ Wu, X.; Zilm, K. W. J. Magn. Reson. 1993, A102, 205.

${ }^{42}$ Palmas, P.; Tekely, P.; Canet, D. J. Magn. Reson. 1993, A104, 26.

${ }^{43}$ Babonneau, F.; Maquet, J.; Bonhomme, C.; Richter, R.; Roewer, G.; Bahloul, D. Chem. Mater. 1996, 8,1415

${ }^{44}$ Wu, X.; Zhang, S. Chem. Phys. Lett. 1989, 156, 79.

${ }^{45}$ Alemany, L. B.; Grant, D. M.; Pugmire, R. J.; Alger, T. D.; Zilm, K. W. J. Am. Chem. Soc. 1983, 105, 2142 
${ }^{46}$ Morris, G. A.; Freeman, R. J. Am. Chem. Soc. 1979, 101, 760-762

${ }^{47}$ Burum, D. P.; Ernst, R. R. J. Magn. Reson. 1980, 39, 163

${ }^{48}$ Fyfe, C. A.; Wong-Moon, K. C.; Huang, Y.; Grondey, H. J. Am. Chem. Soc. 1995, 117, 10397

${ }^{49}$ Alonso, B.; Massiot, D. J. Magn. Reson. 2003, 163, 347

${ }^{50}$ Elena, B.; Lesage, A.; Steuernagel, S.; Boeckmann, A.; Emsley, L. J. Am. Chem. Soc. 2005, 127,17296

${ }^{51}$ Brinkmann, A.; Edén, M.; Levitt, M. H. J. Chem. Phys., 2000, 112, 8539

${ }^{52}$ Lee, Y. K.; Kurur, N. D.; Helmle, M.; Johannessen, O.; Nielsen, N. C.; Levitt, M. H. Chem. Phys. Lett. 1995, 242, 304

${ }^{53}$ Hohwy, M.; Jakobsen, H. J.; Edén, M.; Levitt, M. H.; Nielsen, N. C. J. Chem. Phys. 1998, 108, 2686.

${ }^{54}$ Hohwy, M.; Rienstra, C.M.; Jaroniec, C. P.; Griffin, R. G. J. Chem. Phys. 1999, 110, 7983

${ }^{55}$ States, D. J.; Haberkorn, R. A.; Ruben, D. J. J. Magn. Reson. 1982, 48, 286

${ }^{56}$ Baccile, N.; Laurent, G.; Bonhomme, C.; Innocenzi, P.; Babonneau, F. Chem. Mater. 2007, 19, 1343

${ }^{57}$ Meier, B. H. Advances in Magnetic and optical Resonance, vol. 18, 1, Warren W.S. Ed., Academic Press, New York, 1994.

${ }^{58}$ Schmidt-Rohr, K.; Spiess, H. W. Multidimensional Solid-State NMR and Polymers; p.431 Academic Press: San Diego, 1994.

59 Szeverenyi, N. M.; Sullivan, M. J.; Maciel, G. E. J. Magn. Res. 1982, 47, 462 
${ }^{60}$ Ulbricht, R. J.; Northup, S. J.; Thomas, J. A. Fund. Appl. Toxic. 1984, 4, 843

${ }^{61}$ Lourvanij, K.; Rorrer, G. L. Ind. Eng. Chem. Res. 1993, 32, 11

${ }^{62}$ Lourvanij, K.; Rorrer, G. L. App. Catal. A: General 1994, 109, 14

${ }^{63}$ Asghari, F. S.; Yoshida, H. Ind. Eng. Chem. Res. 2006, 45, 2163

${ }^{64}$ Spectral Database for Organic Compounds, SDBS, National Institute of Advanced Industrial Science and Technology (AIST), Japan

${ }^{65}$ Girisuta, B.; Janssen, L. P. B. M.; Heeres, H. J. Chem. Eng. Res. Des., 2006, 84, 339

${ }^{66}$ Alemany, L. B.; Grant, D. M.; Pugmire, R. J.; Alger, T. D.; Zilm, K. W. J. Am. Chem. Soc., 1983, 105, 2133; Alemany, L. B.; Grant, D. M.; Pugmire, R. J.; Alger, T. D.; Zilm, K. W. J. Am. Chem. Soc., 1983, 105, 2142

${ }^{67}$ Lesage, A.; Auger, C.; Caldarelli, S.; Emsley, L. J. Am. Chem. Soc., 1998, 120, 9059

${ }^{68}$ Lesage, A.; Bardet, M.; Emsley, L. J. Am. Chem. Soc., 1999, 121, 10987

${ }^{69}$ Ishii, Y. J. Chem. Phys., 2001, 114, 8473

${ }^{70}$ Hohwy, M.; Rienstra, C. M.; Griffin, R. G. J. Chem. Phys. 2002, 117, 4973

${ }^{71}$ Grommek, A.; Meier, B. H.; Ernst, M. Chem. Phys. Lett. 2006, 427, 404

${ }^{72}$ Note: diene polymerization would reduce the number of double bonds to $33 \%$, while $4+2$ cycloadditions would result in $50 \% \mathrm{sp}^{2}$-content.

${ }^{73}$ Gandini, A.; Belgacem, M. N. Prog. Polym. Sci. 1997, 22, 1203 